\title{
THE EFFECTS OF A CYANOBACTERIAL TOXIN AND MACROPHYTE COMPOSITION ON AMPHIBIAN PARASITISM
}

\author{
By \\ Marin Milotic \\ Bachelor of Science, 2014, Ryerson University
}

\author{
A thesis \\ presented to Ryerson University \\ in partial fulfillment of the \\ requirements for the degree of Master of Science \\ in the Program of \\ Molecular Science \\ Toronto, Ontario, Canada, 2016 \\ (C) Marin Milotic 2016
}




\section{AUTHOR'S DECLARATION}

I hereby declare that I am the sole author of this thesis. This is a true copy of the thesis, including any required final revisions, as accepted by my examiners.

I authorize Ryerson University to lend this thesis to other institutions or individuals for the purpose of scholarly research.

I further authorize Ryerson University to reproduce this thesis by photocopying or by other means, in total or in part, at the request of other institutions or individuals for the purpose of scholarly research.

I understand that my thesis may be made electronically available to the public. 


\begin{abstract}
The Effects of a Cyanobacterial Toxin and Macrophyte Composition on Amphibian Parasitism Master of Science

2016

Marin Milotic

Molecular Science
\end{abstract}

Amphibians are experiencing global declines with habitat loss and degradation, and infectious diseases as major contributors. Environmental changes such as eutrophication and climate alterations can cause the proliferation of primary producers, including cyanobacteria, and both native and invasive macrophytes. Cyanobacterial blooms can be toxic due to the production of microcystins such as MC-LR, and invasive macrophytes can alter the structural complexity of aquatic habitats - both can affect host-parasite dynamics. I examined the effects of MC-LR on larval amphibian susceptibility to infection by a trematode parasite as well as host growth and anti-parasite behaviour, finding increased susceptibility to infection at low concentrations. I also investigated how MC-LR affected the longevity and activity of trematode infectious stages (cercariae), and demonstrated variable effects among species. Lastly, I examined how environmental structural complexity, modeled as macrophyte complexity and density, affected tadpole infection by a trematode parasite and host anti-parasite behaviour but found no impact. 


\section{ACKNOWLEDGEMENTS}

I owe a tremendous thank you to my supervisor, Dr. Janet Koprivnikar who took on a student who was a little lost. I would also like to thank my supervisor for being one of the most positive people I have ever met, for always being helpful and somehow always managing to weather the storm. I would also like to thank Dr. Koprivnikar for providing guidance, encouragement and making sure everything was kept well on track.

I give my thanks to Dr. Michael Arts and Dr. Lesley Campbell for providing excellent feedback on the process which went into designing my thesis from the early steps until the final steps. I would also like to thank Dr. Arts for the information that MC-LR may bind to plastics. I thank Dr. Katie O'Dwyer and Lucia Santos for taking care of the tadpoles and snails, and for always being cheerful lab-mates.

I must thank my brother Dino for always volunteering when I needed help and for always pushing me when I needed a push.

Lastly, I would like to thank my family and friends for providing encouragement and my parents for always being supportive even when the road was bumpy. 


\section{TABLE OF CONTENTS}

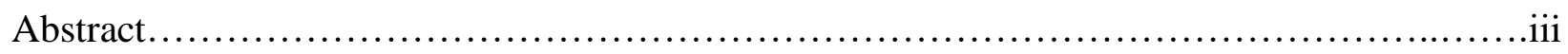

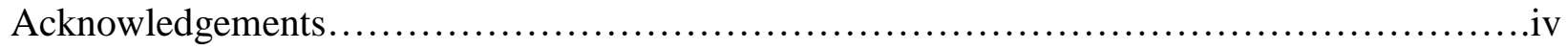

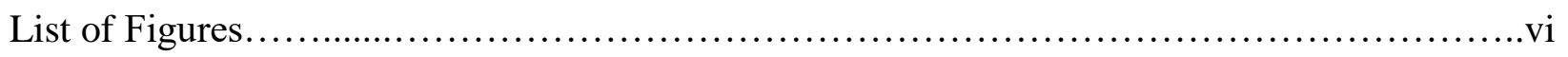

Chapter 1. Amphibians, disease and primary producers...................................

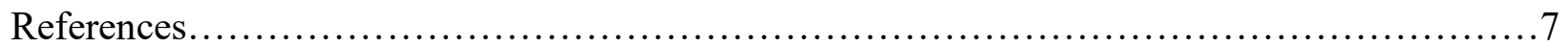

Chapter 2. Effects of microcystin toxins on tadpole susceptibility to parasitism...............11

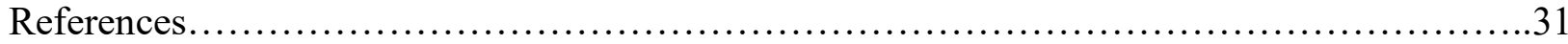

Chapter 3. Effects of cyanobacterial toxins on a parasite infectious stage.....................37

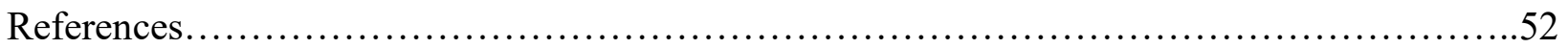

Chapter 4. Effects of macrophyte structural complexity on amphibianparasitism................57

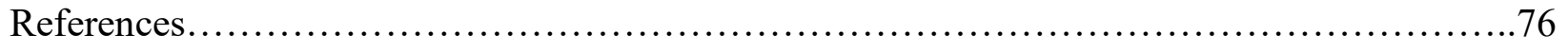

Chapter 5. General Discussion....................................................... 79

References................................................................... 85 


\section{LIST OF FIGURES}

Chapter 1

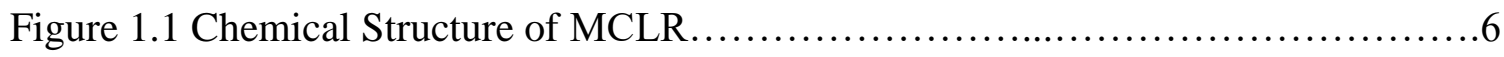

Chapter 2

Figure 2.1 Effect of MC-LR on bullfrog parasitism...............................21

Figure 2.2 Effect of MC-LR on bullfrog growth...............................22

Figure 2.3 Effect of MC-LR on bullfrog anti-parasite behaviour.....................23

Figure 2.4 Effect of MC-R on northern leopard frog survival........................24

Figure 2.5 Effect of MC-LR on northern leopard frog parasitism .....................25

Chapter 3

Figure 3.1 Effect of MC-LR on E. trivolvis cercariae activity and longevity.............44

Figure 3.2 Effect of MC-LR on Trichobilharzia sp. cercariae activity and longevity .....45

Figure 3.3 Effect of MC-LR on armatae-type cercariae activity and longevity ..........46

Figure 3.4 Effect of MC-LR on strigeid-type cercariae activity and longevity ..........47

\section{Chapter 4}

Figure 4.1 Plastic plants and corresponding macrophytes.........................65

Figure 4.2 Low and high density plant arrangements............................66

Figure 4.3 Effect of structural complexity on wood frog parasitism..................67

Figure 4.4 Effect of structural complexity on wood frog infection prevalence ...........68

Figure 4.5 Effect of structural complexity on wood frog anti-parasite behaviour..........70

Figure 4.6 Effect of structural complexity on wood frog proximity to vegetation ........71 


\section{CHAPTER 1: GENERAL INTRODUCTION AMPHIBIANS, DISEASE, AND PRIMARY PRODUCERS}

Amphibians are an integral part of freshwater ecosystems, acting as predators, grazers and prey. A record number of amphibian species have become threatened, extirpated, or extinct in recent years, sparking interest in uncovering the underlying causes of these global declines (Beebee \& Griffiths, 2005; McCallum, 2007). Amphibian declines worldwide are have been attributed to diseases, pollution, land use changes, and climate change (Collins, 2010). Diseases such as the chytrid fungus and ranavirus are known to decimate amphibian populations (Daszak et al., 1999). Trematode parasites (flatworms in the Phylum Platyhelminths) are also diseasecausing organisms of particular concern for amphibians. For instance, Ribeiroia ondatrae and Echinostoma trivolvis are trematodes found in North America that have been shown to cause significant amphibian mortality and pathology in the wild (Johnson et al., 2001; Koprivnikar et al., 2012). Echinostoma trivolvis encysts in the kidneys of amphibians where it causes a loss of renal function (Schotthoefer et al., 2003), and $R$. ondatrae encysts around the tadpole hind-limb buds, causing significant mortality and morbidity in the form of limb deformities (Johnson et al., 2001) which may serve to make the amphibians easier prey and promote transmission to the next host (Goodman \& Johnson, 2011).

Trematodes have a complex life cycle consisting of two or more hosts. They utilize a vertebrate host for sexual reproduction. Eggs are excreted into the aquatic environment via the host where they hatch into miracidia. Free-swimming miracidia seek to infect the first intermediate host - typically an aquatic gastropod where they establish and commence asexual reproduction. Free-swimming infective larval stages called cercariae emerge from the gastropod and seek to infect the second intermediate host which can vary (Olsen, 1989). In the case of $R$. 
ondatrae and E. trivolvis, the second intermediate host is most often a larval amphibian. Once the second intermediate host is infected, cercariae encyst into metacercariae and this host is eaten by the definitive host, where the trematode matures and the cycle repeats (Olsen, 1989). Owing to the complexity of this life cycle, there is great potential for the environment to influence transmission success, including host susceptibility and tolerance to infection, as well as effects on the free-living infectious stages (Pietrock \& Marcogliese, 2003).

Although trematode infections alone are detrimental, an anthropogenically-altered environment can make amphibians more vulnerable to infection and the pathogenic effects associated with parasitism. For example, pesticides have been found to increase amphibian susceptibility to infection by $R$. ondatrae (Kiesecker, 2002) as well to reduce amphibian tolerance to infection once infected (Koprivnikar, 2010). Although larval amphibians rely on their immune system to combat infection, tadpoles also display anti-parasite behaviour in the form of rapid turns and quick swimming to escape or dislodge cercariae (Koprivnikar et al., 2006). As such, susceptibility and tolerance can be affected by anthropogenic chemicals altering host immune parameters, but defence by anti-parasite behaviour can also be affected.

Aside from the hosts experiencing detrimental effects from chemicals in the environment, cercariae are also known to be susceptible to many abiotic factors (Pietrock \& Marcogliese, 2003). Once in the environment, cercariae must find their next host quickly, as their lifespan is usually one day and they only remain infectious for about 8 hours (McCarthy, 1999). Consequently, cercariae are very vulnerable to biotic and abiotic factors which could interfere with their survival and activity. Water temperature, salts, water hardness, and $\mathrm{pH}$ changes can all harm cercariae and thus impede their transmission (Pietrock \& Marcogliese, 2003). Just as anthropogenic chemicals act upon the host, they can also act upon the parasite. For instance, 
Koprivnikar et al. (2006) tested cercariae of different trematode species and found that the pesticide atrazine can increase the mortality of cercariae and decrease their activity and infectivity.

In addition to chemical interference with cercarial host-finding, the physical environment may also play a role in host-parasite interactions. Notably, the littoral (near-shore) zone of water bodies is the area bearing the heaviest burden of trematodes because they heavily rely on macroinvertebrates such as snails to produce and release cercariae (Mouritsen \& Poulin, 2002). Indeed, the physical environment was found to have the potential to disrupt cercarial host-finding in marine systems (Welsh et al., 2014). Shells from various organisms can impede/trap cercariae; however, an effect was only found when the shells were rather complex in shape, such as that of an oyster, which blocked cercariae by up to $44 \%$ compared to smooth and simple shells which had no effect (Welsh et al., 2014). Cercariae can also be trapped by tentacles of sea anemones or seaweed, resulting in a lower infection success (Prinz et al., 2009). Although fish in lakes with macrophytes were found to have lower infection with some parasites (monogeneans) (Viozzi \& Semenas, 2009), the potential blocking effect by the physical structure of macrophytes has not been examined for freshwater trematodes. Examining the potential for macrophyte interference with parasite host-finding is important because invasive macrophytes can reach very high densities and have the potential to completely alter the structural complexity of the environment (Boylen et al., 1996).

In recent years, another aspect of anthropogenic chemicals in aquatic ecosystems that has been of increasing concern worldwide is that of eutrophication. Eutrophication is the result of an over-enrichment of nutrients in a body of water due to runoff from agriculture, industry, or the populace (e.g. through detergents). This over-enrichment promotes cyanobacterial and algae 
blooms which were shown to result in more intense infections in fish (Shah et al., 2014) and amphibians (Johnson et al., 2007), primarily because this promotes the presence of intermediate hosts such as snails for trematodes. However, another concerning part of cyanobacterial blooms is their potential toxicity.

Certain cyanobacteria produce neurotoxins, cytotoxins, irritants and hepatotoxins (Codd et al., 2005). Microcystins (MCs) are hepatotoxins with over 70 different forms, the most common being microcystin-LR (MC-LR, Fig. 1.1) (Zurawell et al., 2005 ; Codd et al., 2005). Cyanobacterial blooms vary in their severity and thus the concentration of MC-LR varies accordingly. Concentrations across the world range from as little as $1 \mu \mathrm{g} / \mathrm{L}$ (Williams et al., 2007) to as high as $6400 \mu \mathrm{g} / \mathrm{L}$ in surface scums (Kotak \& Zurawell, 2007), and are a problem in Canada as well (Orihel et al., 2012). MC-LR can linger in the environment for a long time and overlaps with amphibian breeding times, particularly when larval stages are reliant on aquatic habitats. There have been instances of MC-LR persisting at high concentrations for 2 months (Williams et al., 2007). In addition, it can be sequestered in the sediment (Munusamy, 2012). Thus, the toxin has ample time to come in contact with various aquatic organisms. MC-LR has been found to have detrimental effects on many organisms ranging from protists to birds (Zurawell et al., 2005), but no work has been done on its effect on host-parasite interactions. While it is known that eutrophication can cause increased infection by giving rise to an abundance of snails which produce cercariae (Johnson et al., 2007), the effect of the toxic exudates of cyanobacteria have not been examined. Thus, the toxic chemicals released by phytoplankton, as well as physical obstruction by macrophytes, are both equally important and yet poorly understood mechanisms by which host-parasite interactions could be affected by primary producers. 
In Chapter 1, my aim was to examine whether MC-LR can make larval stages (tadpoles) of two amphibian species (Rana catesbeiana and Rana pipens - bullfrogs and northern leopard frogs) more susceptible to infection by E. trivolvis. I hypothesized that the toxin MC-LR would increase tadpole susceptibility to infection by E. trivolvis, resulting in higher infection intensities. My aim was also to examine the effect of MC-LR on R. catesbeiana anti-parasite behaviour (activity) in the presence of E. trivolvis cercariae. I hypothesized that $R$. catesbeiana would display reduced activity when exposed to MC-LR, leading to increased infection by E. trivolvis cercariae.

In Chapter 2, I examined the effect of MC-LR on the activity and longevity of cercariae from four different species of trematode: an unidentified strigeid-type cercariae, an unidentified armatae-type cercariae, Trichobilharzia sp., and E. trivolvis. I hypothesized that MC-LR would reduce the activity of these cercariae as well as their longevity.

In Chapter 3, I aimed to examine the effects of environmental complexity via macrophytes on $R$. ondatrae infection success in tadpoles, and on the anti-parasite behaviour (activity) of $R$. sylvatica (wood frog) larvae. Environmental complexity was represented by plastic macrophytes that varied in density and structural complexity. I hypothesized that both increased density and complexity of the plants would reduce cercarial host-finding success, resulting in lower infections. I also hypothesized that tadpole activity would be reduced with increasing density and complexity of vegetation, resulting in higher infections. 
Figure 1.1: Chemical Structure of microcystin-LR where (1) is d-alanine; (2) is 1-

Leucine; (3) is D-erythro- $\beta$-methylaspartic acid; (4) is 1-Arginine; (5) is Adda; (6) is d-glutamic acid; and (7) is N-methyldehydroalanine (Zurawell et al., 2005).

(6)

(7)

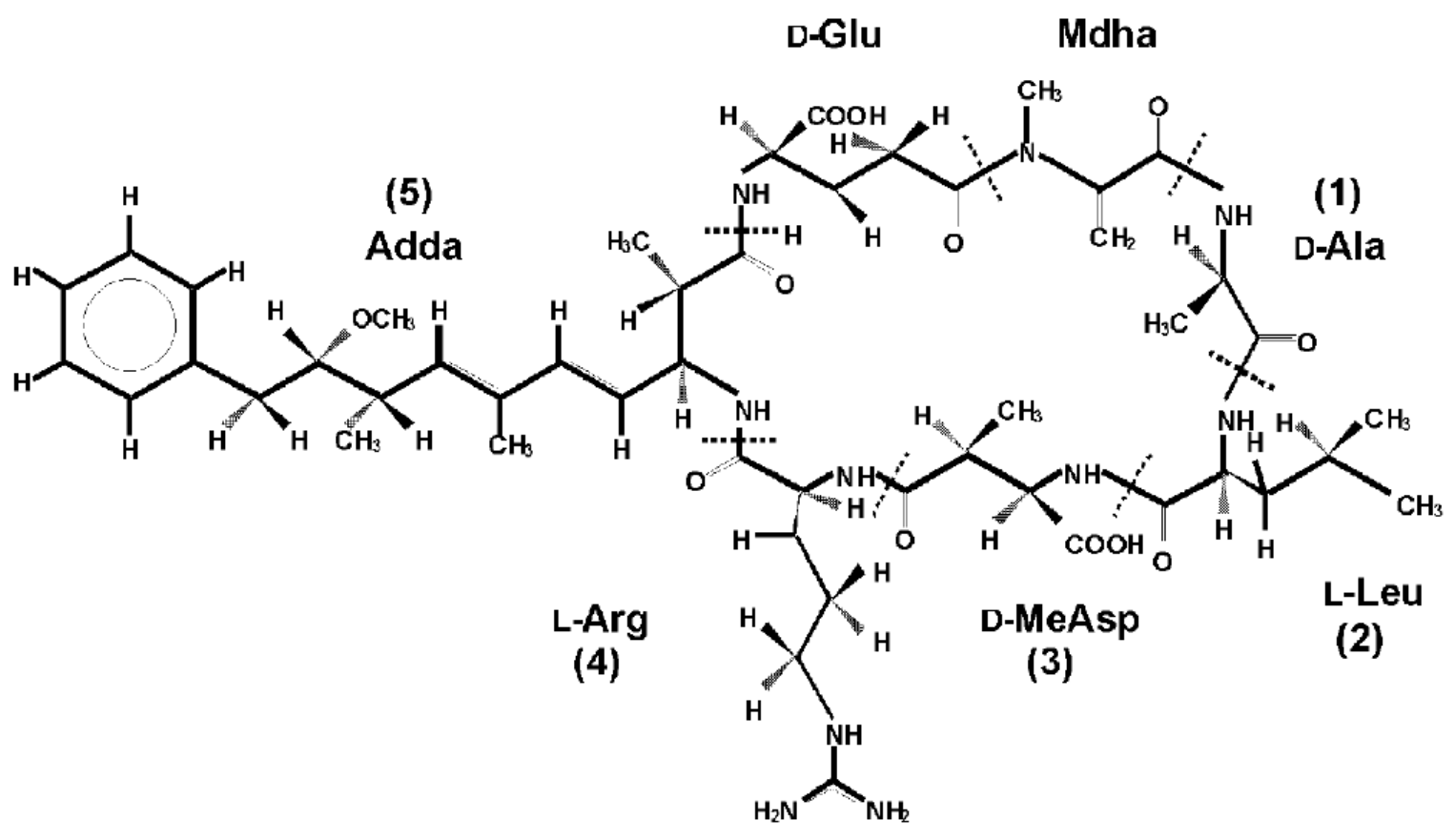




\section{References:}

Beebee, T. J. C., \& Griffiths, R. A. (2005). The amphibian decline crisis: A watershed for conservation biology? Biological Conservation, 125, 271-285.

Boylen, C. W., Eichler, L. W., \& Sutherland, J. W. (1996). Physical control of eurasian watermilfoil in an oligotrophic lake. Hydrobiologia, 340, 213-218.

Codd, G. A., Morrison, L. F., \& Metcalf, J. S. (2005). Cyanobacterial toxins: Risk management for health protection. Toxicology and Applied Pharmacology, 203(3 SPEC. ISS.), 264-272. Collins, J.P., (2010). Amphibian decline and extinction: what we know and what we need to learn. Diseases of Aquatic Organisms, 92, 93-99.

Daszak, P., Berger, L., Cunningham, A.A., Hyatt, A.D., Green, D.E. and Speare, R., (1999). Emerging infectious diseases and amphibian population declines. Emerging Infectious Diseases, 5, 735 .

Johnson, P. T. J., Lunde, K. B., Ritchie, E. G., \& Launer, A. E. (1999). The effect of trematode infection on amphibian limb development and survivorship. Science, 284, 802-804.

Goodman, B. A. and P. T. J. Johnson (2011). Disease and the extended phenotype: parasites control host performance and survival through induced changes in body plan. PLoS ONE 6, e20193

Johnson, P. T. J., Chase, J. M., Dosch, K. L., Hartson, R. B., Gross, J. A., Larson, D. J., Carpenter, S. R. (2007). Aquatic eutrophication promotes pathogenic infection in amphibians. Proceedings of the National Academy of Sciences of the United States of America, 104, 15781-15786.

Johnson, P. T. J., Lunde, K. B., Ritchie, E. G., Reaser, J. K., \& Launer, A. E. (2001). Morphological abnormality patterns in a California amphibian 
community. Herpetologica, 57, 336-352.

Kiesecker, J. M. (2002). Synergism between trematode infection and pesticide exposure: A link to amphibian limb deformities in nature? Proceedings of the National Academy of Sciences of the United States of America, 99, 9900-9904.

Koprivnikar, J., Marcogliese, D.J., Rohr, J.R., Orlofske, S.A., Raffel, T.R. and Johnson, P.T., (2012). Macroparasite infections of amphibians: what can they tell us? EcoHealth, 9, 342360.

Koprivnikar, J., Forbes, M. R., \& Baker, R. L. (2006). Effects of atrazine on cercarial longevity, activity, and infectivity. Journal of Parasitology, 92, 306-311.

Koprivnikar, J. (2010). Interactions of environmental stressors impact survival and development of parasitized larval amphibians. Ecological Applications, 20, 2263-2272.

Kotak, B. G., \& Zurawell, R. W. (2007). Cyanobacterial toxins in Canadian freshwaters: A review. Lake and Reservoir Management, 23, 109-122.

Kuris, A. M., Hechinger, R. F., Shaw, J. C., Whitney, K. L., Aguirre-Macedo, L., Boch, C. A., Lafferty, K. D. (2008). Ecosystem energetic implications of parasite and free-living biomass in three estuaries. Nature, 454, 515-518.

McCallum, M. L. (2007). Amphibian decline or extinction? current declines dwarf background extinction rate. Journal of Herpetology, 41, 483-491.

McCarthy, A.M., (1999). The influence of temperature on the survival and infectivity of the cercariae of Echinoparyphium recurvatum (Digenea: Echinostomatidae). Parasitology, 118, pp.383-388.

Mouritsen, K. N., \& Poulin, R. (2002). Parasitism, community structure and biodiversity in intertidal ecosystems. Parasitology, 124(SUPPL.), S101-S117 
Munusamy, T., Hu, Y., \& Lee, J. (2012). Adsorption and photodegradation of microcystin-LR onto sediments collected from reservoirs and rivers in Taiwan: A laboratory study to investigate the fate, transfer, and degradation of microcystin-LR. Environmental Science and Pollution Research, 19, 2390-2399.

Olsen, O.W., (1986). Animal parasites: Their life cycles and ecology. Courier Corporation. $562 \mathrm{pp}$.

Orihel, D. M., Bird, D. F., Brylinsky, M., Chen, H., Donald, D. B., Huang, D. Y., Vinebrooke, R. D. (2012). High microcystin concentrations occur only at low nitrogen-to-phosphorus ratios in nutrient-rich Canadian lakes. Canadian Journal of Fisheries and Aquatic Sciences, 69, 1457-1462.

Pietrock, M., \& Marcogliese, D. J. (2003). Free-living endohelminth stages: At the mercy of environmental conditions. Trends in Parasitology, 19, 293-299.

Prinz, K., Kelly, T. C., O'Riordan, R. M., \& Culloty, S. C. (2009). Non-host organisms affect transmission processes in two common trematode parasites of rocky shores. Marine Biology, $156,2303-2311$.

Schotthoefer, A.M., Cole, R.A. and Beasley, V.R., (2003). Relationship of tadpole stage to location of echinostome cercariae encystment and the consequences for tadpole survival. Journal of Parasitology, 89, 475-482.

Shah, H. B., Yousuf, A. R., Chishti, M. Z., Shahnaz, S., \& Ahmad, F. (2014). Trophic status and helminth infracommunities of fish populations in kashmir himalayan lakes. Journal of Helminthology, 88, 264-271.

Viozzi, G. P., \& Semenas, L. G. (2009). Do environmental differences between lakes in northwestern argentinean patagonia affect the infection of Philureter trigoniopsis 
(monogenea) in Galaxias maculatus (osmeriformes)? The Journal of Parasitology, 95, 25-31.

Welsh, J. E., Van Der Meer, J., Brussaard, C. P. D., \& Thieltges, D. W. (2014). Inventory of organisms interfering with transmission of a marine trematode. Journal of the Marine Biological Association of the United Kingdom, 94, 697-702.

Williams, C. D., Aubel, M. T., Chapman, A. D., \& D'Aiuto, P. E. (2007). Identification of cyanobacterial toxins in florida's freshwater systems. Lake and Reservoir Management, 23, $144-152$.

Zhang, D., Xie, P., Liu, Y., Chen, J., \& Wen, Z. (2009). Spatial and temporal variations of microcystins in hepatopancreas of a freshwater snail from lake Taihu. Ecotoxicology and Environmental Safety, 72, 466-472.

Zurawell, R. W., Chen, H., Burke, J. M., \& Prepas, E. E. (2005). Hepatotoxic cyanobacteria: A review of the biological importance of microcystins in freshwater environments. Journal of Toxicology and Environmental Health - Part B: Critical Reviews, 8, 1-37. 


\section{CHAPTER 2: EFFECTS OF MICROCYSTIN TOXINS ON TADPOLE SUSCEPTIBILITY TO PARASITISM}

\section{Introduction}

Algal blooms are a worldwide problem and are becoming worse (Paerl \& Huisman, 2009). As mentioned in Chapter 1, certain cyanobacteria (a.k.a. blue-green algae) produce a cocktail of compounds known as microcystins (MCs) which are toxic hepatopeptides with the predominant form being MC-LR (Waajen et al., 2014). Microcystin is thought to be released into the environment mainly due to cell lysis (Zurawell et al., 2016). Due to its toxicity, The World Health Organization (WHO) has set a drinking water limit of $1 \mu \mathrm{g} / \mathrm{L}$, a recreational limit of 20 $\mu \mathrm{g} / \mathrm{L}$ and a limit of $100 \mu \mathrm{g} / \mathrm{L}$ where contact with water must not be made (http://apps.who.int/iris/bitstream/10665/44584/1/9789241548151_eng.pdf). The drinking water standard of Health Canada is $1.5 \mu \mathrm{g} / \mathrm{L}$ (http://www.hc-sc.gc.ca/ewh-semt/pubs/watereau/sum_guide-res_recom/index-eng.php).

In water bodies across Canada and the U.S., microcystin concentrations have a wide range. Of 50 sampled lakes in Florida, MC-LR concentrations ranged from 0.1 to $31 \mu \mathrm{g} / \mathrm{L}$ but in some lakes rose to a concentration of $2780-5700 \mu \mathrm{g} / \mathrm{L}$ in the following year with such concentrations persisting for 2 months (Williams et al., 2007). In Missouri reservoirs, the MCLR concentration was found to be $20 \mu \mathrm{g} / \mathrm{L}$ (Graham \& Jones, 2009). In a review of Canadian microcystins, Zurawell and Kotak (2007) state that the prevalence of MC-LR in Albertan water bodies can be as high as $62 \%$ with shoreline scum sample concentrations reaching up to 6400 $\mu \mathrm{g} / \mathrm{L}$ (Kotak \& Zurawell, 2007). In Ontario, 60\% of the 50 different samples found microcystin concentrations reaching $20 \mu \mathrm{g} / \mathrm{L}$ (Kotak \& Zurawell, 2007) while $26 \%$ of the sites contained more than $50 \mu \mathrm{g} / \mathrm{L}$. Two sites contained concentrations of $394 \mu \mathrm{g} / \mathrm{L}$ and $607 \mu \mathrm{g} / \mathrm{L}$ (Kotak \& 
Zurawell, 2007), respectively. The concentrations were highest in the littoral zone, but there were cases of concentrations above $50 \mu \mathrm{g} / \mathrm{L}$ in open water when a large bloom occurred, stretching several thousand square kilometers. In 2010, MC concentrations in Lake Ontario ranged from $0.2 \mu \mathrm{g} / \mathrm{L}$ to $59.4 \mu \mathrm{g} / \mathrm{L}$ (Perri et al., 2015).

In another study, Orihel et al. (2012) found concerning levels of microcystins in British Columbia, Alberta, Saskatchewan, Manitoba, Ontario, Quebec, Newfoundland and Labrador, New Brunswick, Nova Scotia, and Prince Edward Island, reaching up to $2153 \mu \mathrm{g} / \mathrm{L}$ at some sites. Warm and shallow prairie lakes with lots of nutrient loading were most severe. It was found that across Canada, $41 \%$ of sampled lakes had a microcystin concentration higher than the drinking water guideline of the WHO, and 35\% of sampled lakes had a higher concentration than Health Canada drinking water guidelines. Moreover, $9 \%$ of lakes exceeded the recreational guideline of $20 \mu \mathrm{g} / \mathrm{L}$. Recently, it was found that Lake Erie had microcystin concentrations ranging from 0.003 to $1221.2 \mu \mathrm{g} / \mathrm{L}$ (Steffen et al., 2014). The problem seems to be getting worse with climate change (Paerl \& Huisman, 2009) as these record concentrations in Lake Erie were found to range from 0.1 to $8.7 \mu \mathrm{g} / \mathrm{L}$ to a high of 4,500 $\mu \mathrm{g} / \mathrm{L}$ in surface scum (Michalak et al., 2013). Steffen et al. (2014) suggested that the large range of the reported values may be due to different sampling methods and the ability of the blooms to move both vertically and horizontally such that samples may often be taken outside of the actual bloom. A major problem with MC-LR is its fairly long residence time. Its half-life was found to be 9 days (Lahti et al., 1997), although another study found the toxin present even 21 days after application of an algicide (Jones \& Orr, 1994). MCLR also has the ability to be sequestered in the sediment (Munusamy, 2012). This means that organisms stay in contact with the toxin for an extended period of time. 
Microcystins have been found to be harmful for many organisms (Zurawell et al., 2005). For example, microcystins negatively affect development and body weight in various fish while also causing an enlargement of hepatocytes and tissue necrosis (Zurawell et al., 2005). In the African Clawed frog, a significant negative effect on the mass of tadpoles was observed after four days of exposure to a concentration of $2000 \mu \mathrm{g} / \mathrm{L}$ (Fischer \& Dietrich, 2000). Supporting this finding, Ziková et al. (2013) used older African Clawed frogs and found lower mass of frogs after 12 days of exposure to $31.7 \mu \mathrm{g} / \mathrm{L}$ MC-LR compared to the control.

There are also many examples of invertebrates affected by microcystins. In insects, the toxicity of MC-LR was comparable to the insecticides rotenone, malathion, and carbofuran (Delaney \& Wilkins, 1995). Phantom midge larva experienced mortality when they were fed Daphnia spp. which fed on toxic cyanobacteria (Laurén-Määttä et al., 1995). Gérard et al. (2008) found a significant drop in the abundance and species richness of snails in the presence of toxic cyanobacterial blooms. Further, they found MC-LR accumulated in snail tissues, where an accumulation in the gonadal tissue can cause a decrease in the number of eggs produced (Lance et al., 2010). MC-LR has even been found to affect plants, for example, inhibiting the growth of macrophytes as well as causing a stress response which reduces photosynthesis (Zurawell et al., 2005). Aside from multi-cellular organisms, small organisms such as protists may also be affected. Mortality, damaged cytoskeletal integrity, and induction of resistant spores were observed in Acanthamoeba castellanii, a parasitic amoeba, after ingesting microcystin-producing cyanobacteria (Urrutia-Cordero et al., 2013). In Chapter 3, it is shown that MC-LR can also have a negative effect on the survival and activity of a free-living infectious stage (cercariae) of trematode (flatworm) parasites. 
Although microcystins are clearly toxic to various organisms, this might also affect diseases, such as by altering host-parasite interactions. Many past studies have shown that exposure to toxic chemicals can increase the virulence of pathogens (Galloway \& Depledge, 2001). For instance, when Daphnia magna was exposed to two endoparasites in the presence of sublethal concentrations of the pesticide carbaryl, there was accelerated castration and mortality of the host, likely due to a lowered host resistance to infection (Coors et al., 2008). The same pattern is observed in amphibians, where exposure to the pesticide atrazine has been shown to increase tadpole susceptibility, and reduce tolerance to, trematode infections (Kiesecker, 2002; Koprivnikar, 2010). Dealing with toxins can stress the host, forcing it to allocate resources to coping with the contaminant and leaving less energy to fight the parasite. As an example, it has been shown that chronically stressed amphibians have increased parasite infections (LaFonte \& Johnson, 2013).

Studying factors affecting amphibian decline is critical, as amphibians are in a global decline world-wide (Beebee \& Griffiths, 2005). One of the main contributing factors to the global amphibian decline are various diseases, including trematodes (Daszak et al., 2003). For example, Ribeiroia ondatrae is known to cause severe limb deformities in amphibians, as well as mortality (Johnson et al., 1999). Echinostoma trivolvis also reduces survival but inhibits renal function (Schotthoefer et al., 2003). The toxic effect of microcystins in amphibians may thus act as an additional stress which can facilitate increased infection with severe implications.

Along with immune-mediated aspects of resistance and tolerance to parasites, tadpoles display effective anti-parasite behaviours such that factors which reduce tadpole activity can increase infection (Koprivnikar et al., 2006). For instance, anesthetized hosts unable to exhibit anti-parasite behaviour had higher infection by trematodes, presumably because they were 
unable to avoid or dislodge the swimming cercariae (Daly \& Johnson, 2011). In addition to examining whether contaminants can compromise host immune systems and make them more susceptible to infection, it is also important to study whether exposure has the potential to reduce tadpole activity and increase infection through this mechanism. In this study, I aimed to examine whether ecologically relevant concentrations of MC-LR altered the susceptibility of larval Rana catesbeiana (American bullfrog) and Rana pipiens (northern leopard frog) to infection by a trematode parasite.

\section{Materials and methods}

\section{Tadpole rearing}

A few dozen bullfrog tadpoles at approximately Gosner developmental stages 25-27 (Gosner, 1960) were obtained from a field site in St. Catherines, Ontario in August 2015 and then transported to the animal facility at St. Michael's Hospital in Toronto. Tadpoles were kept in $15 \mathrm{~L}$ communal tubs (50 tadpoles per tub) on a 14:10 light/dark cycle at $22{ }^{\circ} \mathrm{C}$. Water was aerated with airstones and treated with Nutrafin ${ }^{\circledR}$ water conditioner to remove chlorine and chloramine, as well as Biosupport® to promote the growth of beneficial bacteria. Tadpoles were fed raw spinach ad libitum. Water was changed every two days with alternating full water changes and half water changes. In May 2016, northern leopard frog egg masses were obtained from a commercial supplier (Boreal Science) and were reared in $15 \mathrm{~L}$ plastic tubs containing treated water on a 14:10 light/dark cycle until hatching. Hatched tadpoles were then separated into twelve aerated tubs containing treated water at densities of $\sim 70$ tadpoles per tub. Tadpoles were fed boiled spinach and 2-3 pieces of rabbit chow (Haagen $\left.{ }^{\circledR}\right)$ every other day for about three weeks after which they were only fed boiled spinach. All tubs received water changes every two days, with alternating half and full water changes. 


\section{Parasite acquisition}

Several hundred aquatic snails (Helisoma trivolvis) were collected from two ponds near

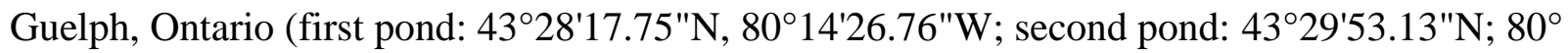
7'14.60"W). Collected snails were screened for trematode infection by placement in a Petri dish with treated water and a piece of spinach. The snails were exposed to a $60 \mathrm{~W}$ incandescent lamp for 1 hour to stimulate the release of cercariae. Echinostoma trivolvis was identified using a compound microscope. Echinostome-infected snails were separated from uninfected snails. Infected snails were kept in communal tubs with treated water at a density of 10 snails per tub and were fed raw spinach ad libitum. On the day of host exposure to parasites, echinostomeinfected snails were placed in a Petri dish under lamps as described above. After 1 hour, actively swimming cercariae were pipetted into microcentrifuge tubes such that there were 20 cercariae per tube. Cercariae were randomly selected from snails to ensure random genetic diversity. No cercariae were older than 3 hours to ensure infectivity.

\section{Experimental setup}

For the experiment with bullfrog tadpoles, $1 \mathrm{mg}$ of pure MC-LR was obtained from a commercial supplier (MJS Biolynx) and dissolved in $1 \mathrm{~mL}$ of methanol. A $1 \mathrm{~L}$ stock solution of $1000 \mu \mathrm{g} / \mathrm{L}$ MC-LR was made by dissolving $1 \mathrm{~mL}$ of this solution in $999 \mathrm{~mL}$ of water. This stock solution was then diluted to create another working solution of $100 \mu \mathrm{g} / \mathrm{L}$ that could be further diluted. Four treatments were chosen to reflect environmentally relevant concentrations: 1) control (water), 2) solvent control (100 $\mu \mathrm{g} / \mathrm{L}$ methanol - corresponding to the highest MC-LR solution), 3) low MC-LR concentration (10 $\mu \mathrm{g} / \mathrm{L})$, and 4) high MC-LR concentration (100 $\mu \mathrm{g} / \mathrm{L})$. The $100 \mu \mathrm{g} / \mathrm{L}$ treatments were made by taking $50 \mathrm{~mL}$ of the $1000 \mu \mathrm{g} / \mathrm{L}$ stock and placing it into $450 \mathrm{~mL}$ of treated water in a series of $500 \mathrm{~mL}$ Mason jars. Glass jars were necessary as MC-LR 
can bind to plastics. The $10 \mu \mathrm{g} / \mathrm{L}$ treatment made by taking $50 \mathrm{~mL}$ of $100 \mu \mathrm{g} / \mathrm{L}$ working solution and placing it in $450 \mathrm{~mL}$ treated water in a series of jars. As outlined in Chapter 1, these concentrations were chosen to reflect commonly found MC-LR concentrations in mild blooms $(10 \mu \mathrm{g} / \mathrm{L})$ and more severe, but not extreme blooms, at $100 \mu \mathrm{g} / \mathrm{L}$. Each treatment had 15 replicates with an ID number (1-60) assigned to it using a random number generator to allow for random placement on shelving.

From the communal tubs, bullfrog tadpoles at stage 25 were selected and randomly placed into a treatment such that there was one tadpole per replicate (sample size of 15 per treatment). Tadpoles were fed boiled spinach ad libitum and were in treatment solutions for 7 days. After 7 days, the jars were placed under two digital video recording cameras in a sequential order according to their ID (1-60) and were wrapped in tinfoil to prevent tadpoles from disturbing each other during recording. White cardboard blinds were placed around the cameras to prevent tadpoles from seeing the experimenters to prevent any influence on tadpole behaviour. A 15 minute acclimation period was allowed. After acclimation, the tadpoles were recorded for 15 minutes without parasites, and were then recorded for another 15 minutes after the addition of 20 E. trivolvis cercariae to each of the jars. A higher number of cercariae was not added because tadpole mortality significantly increases when cercariae intensity is above 20 (Schotthoefer et al., 2003). The jars were then returned to the assigned position on the shelf and the tadpoles were fed spinach ad libitum. After 2 days to allow parasite encystment, tadpoles euthanized in a buffered solution of $1 \%$ MS-222, weighed, and then individually frozen in labelled ziplock bags.

For the experiment conducted with northern leopard frogs in May 2016, the same four treatments were used with the exception of ethanol as the solvent rather than methanol. As above, there were 15 replicates/treatment. The same general experimental procedures were 
followed as for the bullfrog tadpoles but exposure to treatments was only for 5 days owing to high mortality in the highest MC-LR concentration (see Results), and tadpole behaviour was not recorded. Samples of the treatment solutions for both experiments were sent for analysis of MCLR concentration to the Analytical Services Division at the University of Guelph but only results for the 2015 experiment were available at this time.

\section{Data collection and analysis}

All tadpoles were thawed prior to dissections. First, the Gosner developmental stage (Gosner, 1960) of each tadpole was determined under a dissecting microscope. The natural background infection of each bullfrog tadpole with the trematode Ribeiroia ondatrae was determined by examining the hind limb area as well as the mouth. Each experimental tadpole (bullfrog and northern leopard frog) was then dissected to examine the kidneys and protonephridia for experimental infections of E. trivolvis. Because the wild-caught bullfrog tadpoles could have had natural infections to begin with, an additional 20 tadpoles from the same batch were dissected to determine the background level of echinostome infection. The average background echinostome infection intensity of these additional tadpoles (1.2 cysts/tadpole overall, but mean of 3 only considering the $8 / 20$ that were infected) was deducted from the echinostome infection intensities of the experimental tadpoles to obtain a corrected value. This was not necessary for the northern leopard frogs as they were lab-reared from eggs. To analyse bullfrog tadpole behaviour, I determined whether they were active or not every 20 second during the 15 min recording period and then calculated the proportion of time points active.

To determine the effect of MC-LR on the bullfrog tadpoles, I used a multiple analysis of variance (MANOVA) in a General Linear Model (GLM) procedure to look for an overall effect

on three dependent measures: growth (final mass - initial mass/ initial mass), corrected intensity 
of infection, and activity in the presence of parasites. A MANOVA was used because several factors could have contributed to the results, such as the background echinostome infections as well as background $R$. ondatrae infections. Both cyst intensity and growth met the assumption of normal distribution so no transformations were done, but activity was arcsine squareroottransformed because it did not. Treatment was the fixed effect and I also included Gosner developmental stage and number of $R$. ondatrae cysts as covariates. Survivorship was high for bullfrogs (only 1 tadpole died), so mortality was not examined.

To examine the mortality of $R$. pipiens tadpoles in the various treatments, I used an ANOVA with the GLM procedure. Mortality (yes/no) was used as the dependent variable with a binomial distribution and logit link function, entering treatment as the fixed effect. I then looked at the effect of treatment on infection intensity of the surviving tadpoles with another ANOVA but excluded those from the high MC-LR treatment due to almost total mortality. The dependent variable was number of cysts/tadpole using a Poisson distribution and log link function, with treatment as the fixed effect and developmental stage as a covariate.

\section{Results}

\section{Bullfrogs}

There was a trend for MC-LR exposure to have an overall effect on bullfrog tadpoles when considering all 3 dependent variables (Wilk's $\lambda=0.751, \mathrm{~F}_{9,121}=1.689, \mathrm{P}=0.099$ ). Based on the univariate tests for between-subjects effects, treatment had a marginally insignificant effect on corrected cyst abundance $\left(\mathrm{F}_{3,52}=2.702, \mathrm{P}=0.055\right)$ (Fig. 2.1). Posthoc comparisons indicated a significant difference between the control and solvent control $(\mathrm{P}=0.012)$, the control and low MC-LR $(\mathrm{P}=0.039)$, and control and high MC-LR $(\mathrm{P}=0.036)$. The mean corrected intensity of echinostome cysts was $7.09 \pm 4.13$ S.D. (all tadpoles infected). With respect to 
tadpole growth, there was no significant effect of treatment $\left(\mathrm{F}_{3,52}=1.192, \mathrm{P}=0.139\right)$, but a trend for the least mass loss in the control (Fig 2.2). Finally, there was no significant effect of treatment on tadpole activity in the presence of cercariae $\left(\mathrm{F}_{3,52}=1.406, \mathrm{P}=0.251\right)$ (Fig. 2.3). Results of the treatment solution analysis found no MC-LR in the control or solvent control, and concentrations of $11 \mathrm{ug} / \mathrm{L}$ and $82 \mathrm{ug} / \mathrm{L}$ for the low and high MC-LR treatments, respectively. Northern leopard frogs

There was a significant effect of treatment on the mortality of $R$. pipiens tadpoles (Wald $\left.\mathrm{X}^{2}=23.289, \mathrm{df}=2, \mathrm{P}<0.001\right)$ that was driven by the almost-total death of tadpoles in the high MC-LR treatment where only 4/15 survived the exposure (Fig. 2.4). Treatment had a significant effect on cyst intensity (Wald $\mathrm{X}^{2}=10.992, \mathrm{df}=2, \mathrm{P}=0.004$ ) as posthoc tests found a significant difference between the control and low MC-LR solution $(\mathrm{P}=0.023)$, and also between the solvent control and low MC-LR $(\mathrm{P}=0.001)$, but not between the control and solvent control $(\mathrm{P}=$ 0.256)(Fig. 2.5). The mean corrected intensity of echinostome cysts was $7.09 \pm 4.12$ S.D. (all surviving tadpoles infected). 
Figure 2.1: The effect of treatment $(1=$ control, $2=$ solvent control, $3=$ low MC-LR, and $4=$ high MC-LR) on cyst abundance (mean \pm S.E.) in bullfrog tadpoles.

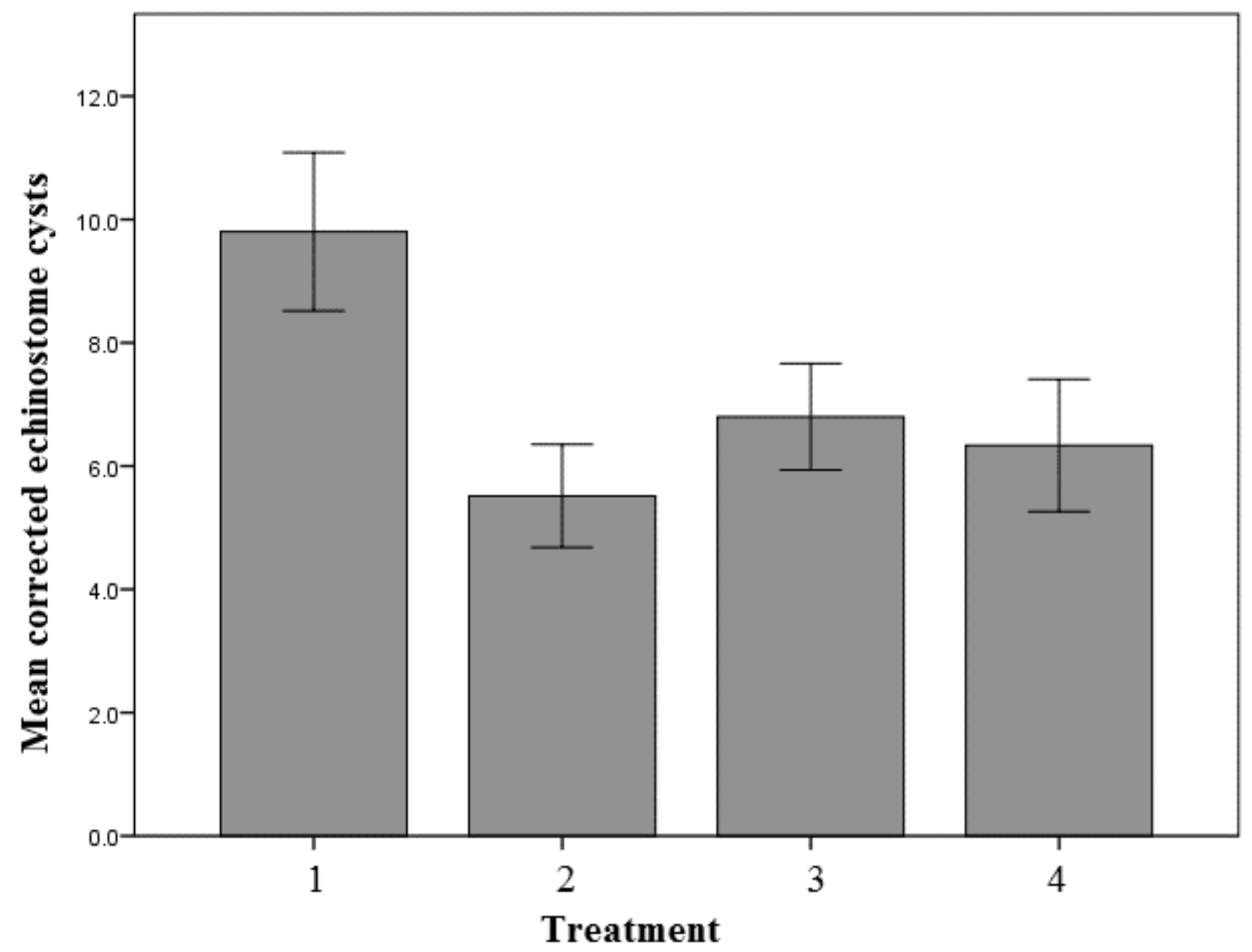

Error Bars: +/- $1 \mathrm{SE}$ 
Figure 2.2: The effect of treatment $(1=$ control, $2=$ solvent control, $3=$ low MC-LR, and $4=$ high MC-LR) on $\%$ growth (mean mass change \pm S.E.) in bullfrog tadpoles.

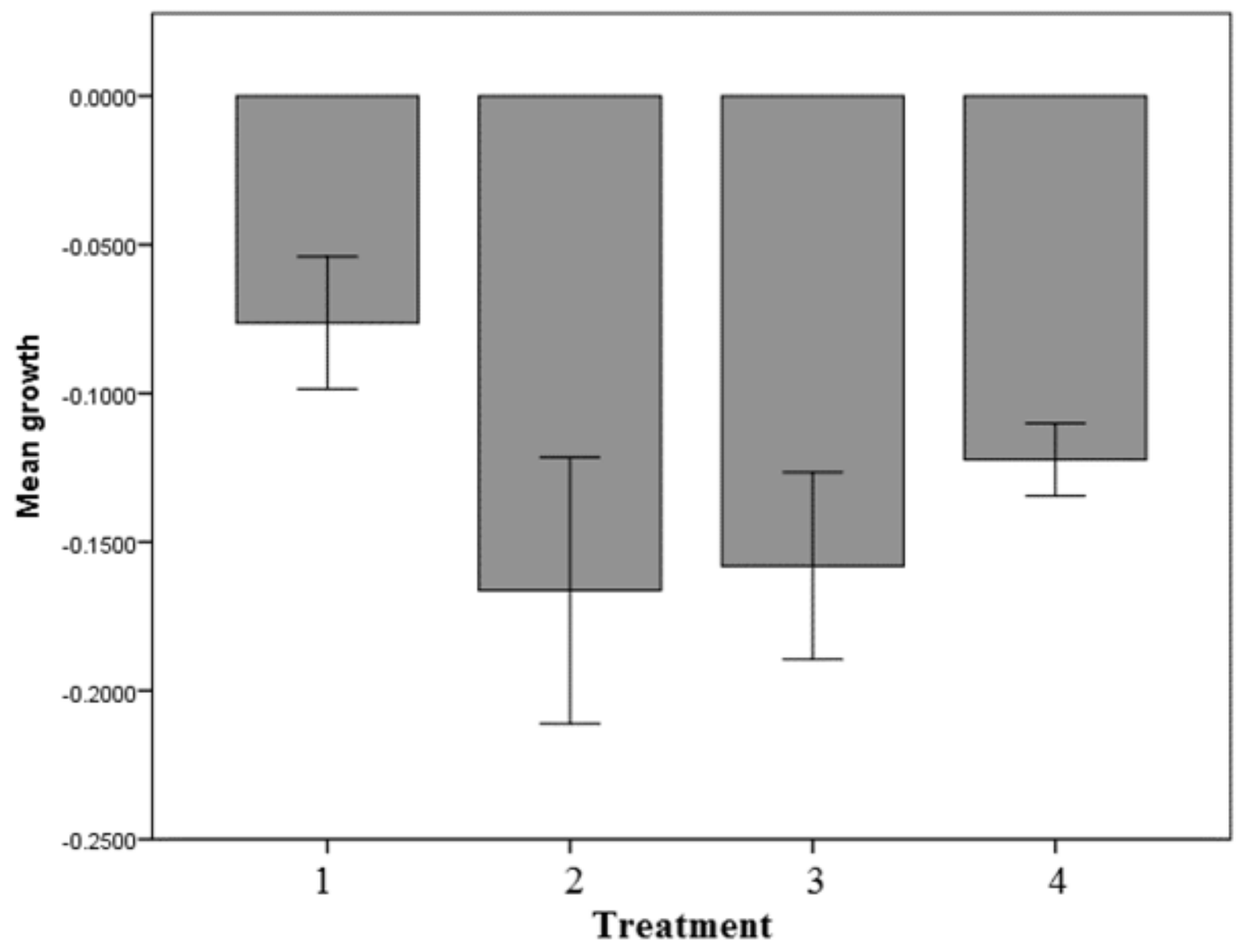

Error Bars: + +- $1 \mathrm{SE}$ 
Figure 2.3: The effect of treatment $(1=$ control, $2=$ solvent control, $3=$ low MC-LR, and $4=$ high MC-LR) on activity (mean proportion of time active \pm S.E.) in bullfrog tadpoles.

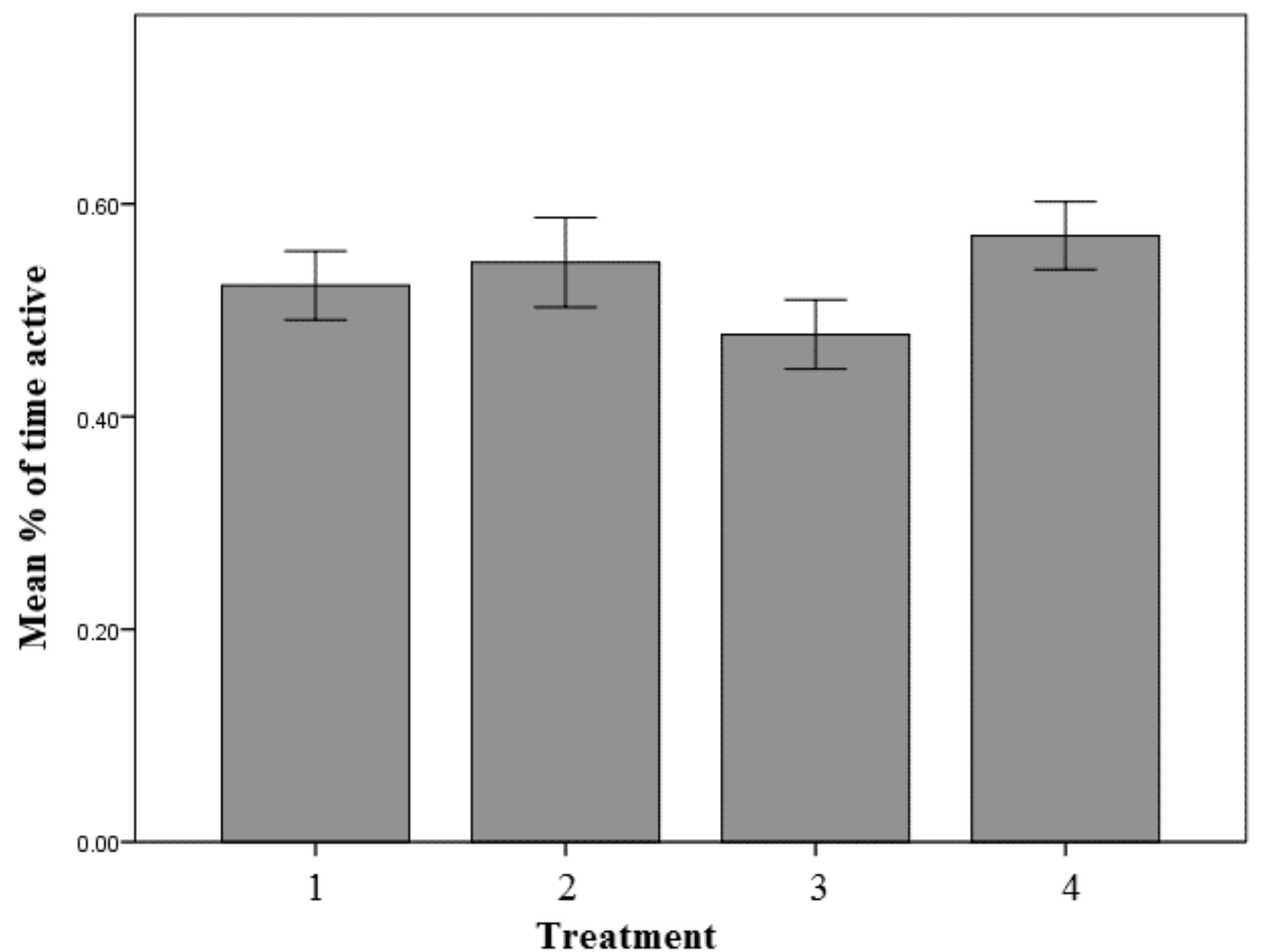

Error Bars: +/- $1 \mathrm{SE}$ 
Figure 2.4: The effect of treatment $(1=$ control, $2=$ solvent control, $3=$ low MC-LR, $4=$ high MC-LR) on mortality in northern leopard frog tadpoles (number alive at end of treatment exposure period).

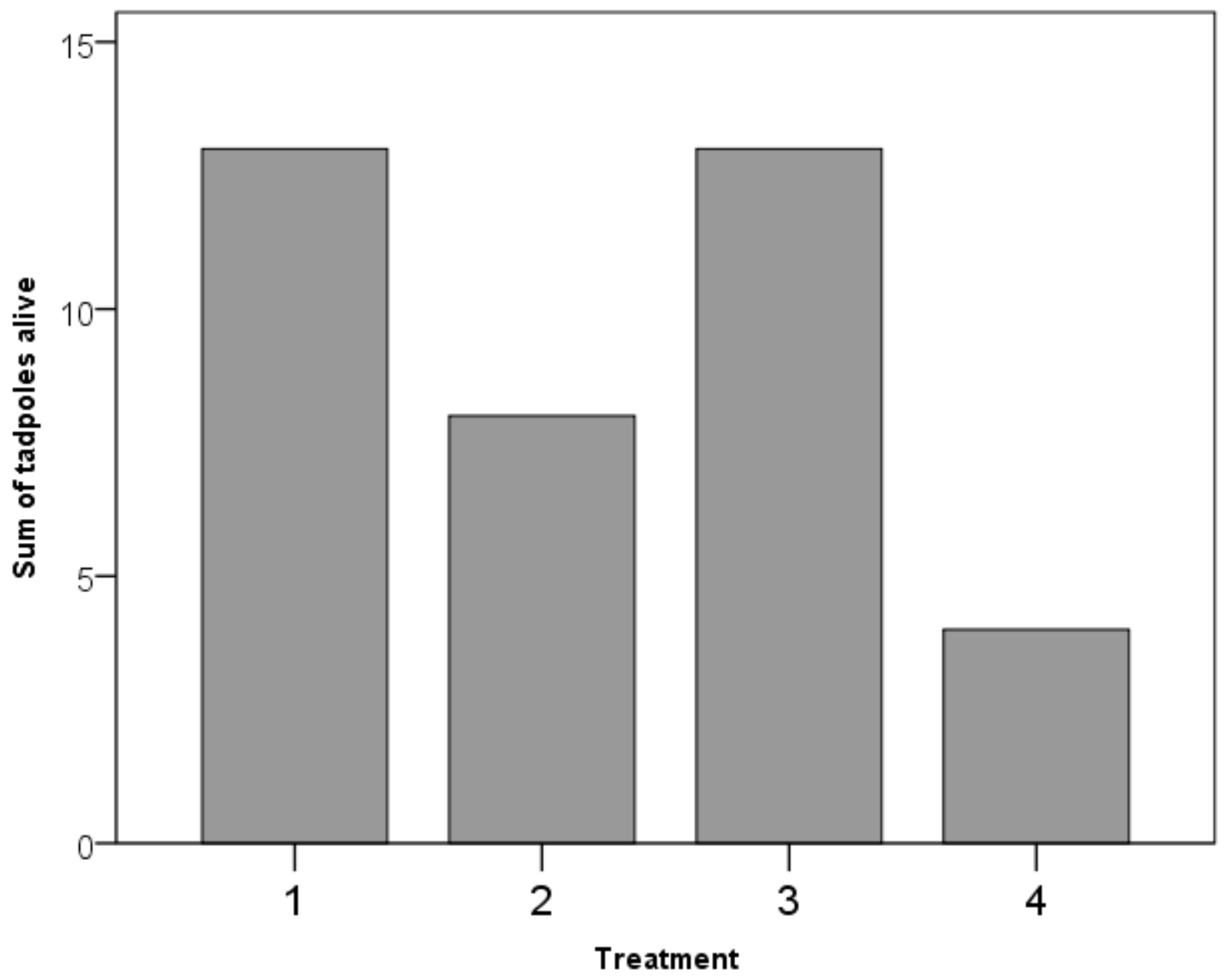


Figure 2.5: The effect of treatment $(1=$ control, $2=$ solvent control, and $3=$ low MC-LR) on cyst abundance (mean \pm S.E.) in northern leopard frog tadpoles.

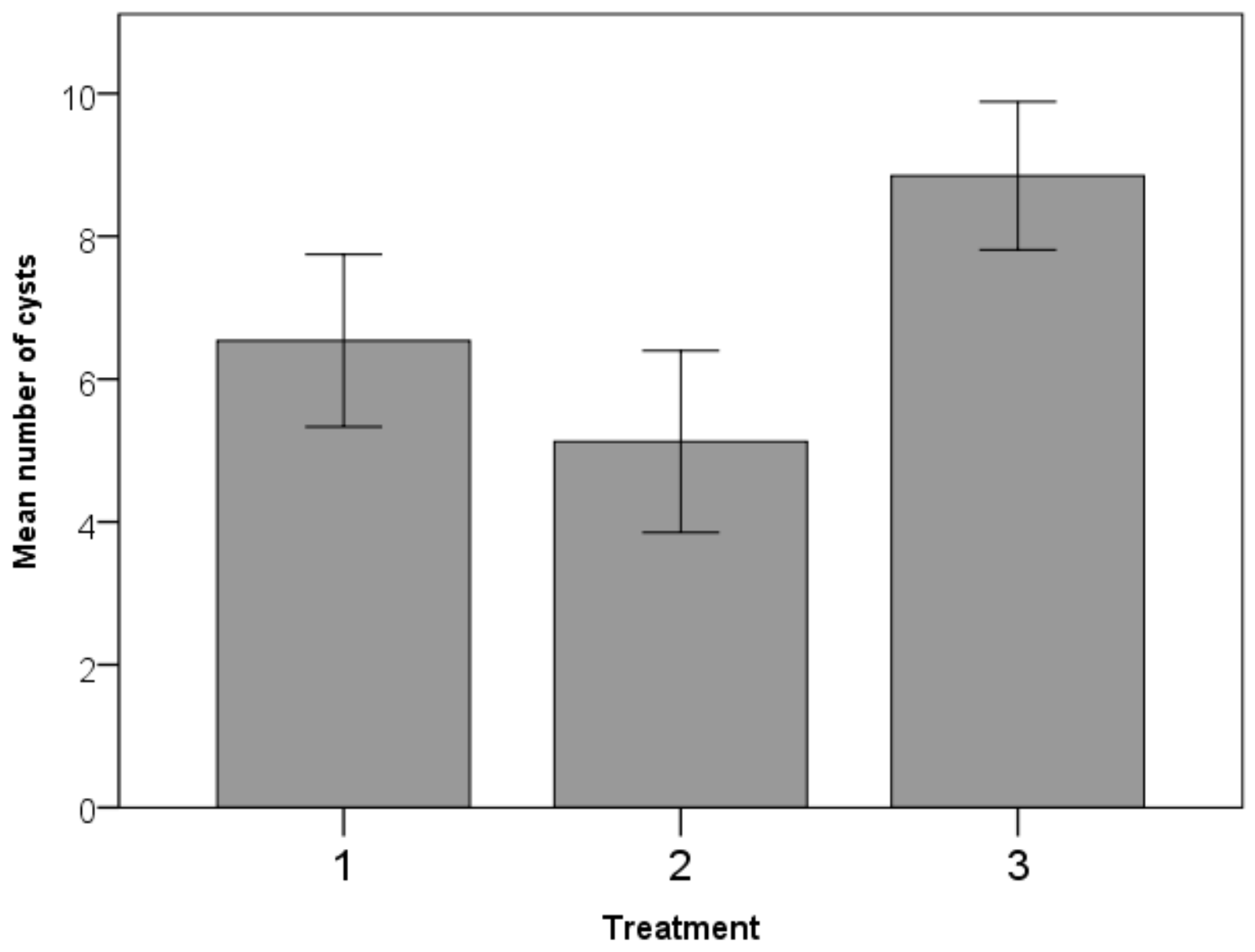

Error Bars: +/- $1 \mathrm{SE}$ 


\section{Discussion}

MC-LR had a significant and marginally insignificant effect on trematode parasite infection in northern leopard frogs (Rana pipiens) and bullfrogs (Rana catesbeiana), respectively. This may be explained by stress and toxin-induced tadpole susceptibility to infection, as with pesticides (Kiesecker, 2002; Koprivnikar, 2010). It is possible that when exposed to MC-LR, tadpoles experienced toxicity and were thus stressed. To survive, stressed organism engage in coping mechanisms. In this case, this may include active excretion of MCLR and repairing damaged tissues, which costs energy. In another study, it was shown that chronically stressed tadpoles were more susceptible to trematode parasitism (LaFonte \& Johnson, 2013). Thus, tadpoles could allocate less of their energy reserves into the immune system to deal with the other factor - MC-LR - leading to increased susceptibility to infection. It was shown that contaminants can affect amphibian parasitism through various mechanisms (Koprivnikar et al., 2007). While anti-parasite behaviour in bullfrogs was not affected by treatment, no measurements were done to examine the blood profile of tadpoles. A blood profile could provide a clear picture of whether MC-LR had any effect on the immune system but a blood profile could also be used to examine stress hormones. Since these measurements were not done, and because MC-LR does not seem to affect tadpole behaviour, the mechanisms by which MC-LR acts to increase infection is unknown.

Previous studies have found that MC-LR exposure can fundamentally alter biochemical pathways in amphibians. MC-LR has been found to be a potent and specific inhibitor of serine/threonine phosphatases - protein phosphatase-1 and protein phosphatase -2A (PP-1 and PP-2A) (MacKintosh et al., 1990). To make matters worse, the binding can be irreversible (Dietrich \& Hoeger, 2005). Protein phosphatases are critical players in biochemical pathways. 
PP-1 plays a role in regulating various important cellular functions such as the proper functioning of membrane receptors and channels, regulating the cell cycle and mitosis by controlling microtubule dynamics, as well as regulating glycogen metabolism (Tournebize et al., 1997; Fong et al., 2000). PP-2A also plays a role in the cell cycle, regulating microtubule length in mitosis (Tournebize et al., 1997), signaling pathways, and cell differentiation (Liu et al., 2003). Thus, inhibiting proper cell cycle progression, cell signaling, receptors and microtubule dynamics has serious implications. Fischer \& Dietrich (2000) found a decrease in PP1 and PP2A activity in the embryo-larval tadpole stages of the African Clawed frog after only 96 hours of exposure to $2000 \mu \mathrm{g} / \mathrm{L}$ MC-LR, indicating an increased PP-inhibiting effect in tadpoles posthatch.

However, another explanation for the effect of MC-LR on bullfrogs was the exposure to methanol in the solvent control and MC-LR treatments. Although there was a significant difference in cyst abundance between the control and all the other treatments for bullfrogs, there was no significant difference between the solvent control and the two MC-LR treatments, implying that the solvent may have played a role in the observed effects. In this experiment with bullfrogs, the lids were kept on the containers to maintain solution levels, perhaps not allowing methanol to evaporate. As such, there could have been a combined effect of MC-LR and methanol. In contrast to the bullfrogs, ethanol was used in the experiment with northern leopard frogs. There was a significant difference in infection between the control and low MC-LR concentration while there was no difference in infection between the control and solvent control. The low MC-LR treatment had an ethanol concentration of only $10 \mu \mathrm{g} / \mathrm{L}$ and the containers were left open to air for 24-hours for ethanol to evaporate. Additionally, the containers were left open 
to air throughout the whole exposure time. In all, this indicates a true effect of MC-LR rather than the solvent.

The growth and activity of bullfrogs were unaffected by the treatments, although mass loss was least in the control. Similar to my results, Chernoff et al. (2002) exposed Bufo arenarum to $1000-20,000 \mu \mathrm{g} / \mathrm{L}$ MC-LR at stage 17 (Gosner, 1960) and also found no effect on growth or development. In contrast to the bullfrogs, very high mortality was observed in $R$. pipiens tadpoles when exposed to $100 \mu \mathrm{g} / \mathrm{L}$ MC-LR. Many studies have examined the toxic effects of microcystins in various organisms and have found a range of detrimental effects (Zurawell et al., 2005). For example, ATPase activity of the $\mathrm{Na}^{+} / \mathrm{K}^{+}$pump in the gills of carp was inhibited by MC-LR (Zambrano \& Canelo, 1996). This effect is believed to cause a loss of gill function and results in fish kills, such as those commonly found during algal blooms (Zambrano \& Canelo, 1996). Microcystins have been found to affect development and body weight in various fish while also causing an enlargement of hepatocytes and tissue necrosis (Zurawell et al., 2005). There are also many examples of MC-LR causing damage to the intestines and kidneys of various organisms (Zurawell et al., 2005), thus, MC-LR can cause widespread organ damage. Lastly, MC-LR causes a loss of cytoskeletal structure in affected cells and is a tumor promoter (Codd, 2000). In snails, microcystins concentrated in the spermatozoids, oocytes, intestines and hepatopancreas (Lance et al., 2010). Although this toxin primarily damages the liver, it can harm many areas of the body. It is thought that hepatopeptides cannot easily pass through membranes via passive diffusion and instead utilize transporters such as the bile-acid transporter mechanism (Eriksson et al., 1990), which is found in the liver and intestine. This is primarily why the toxic effect of MC-LR is centred around indirect or direct effects on the liver, and could be the 
mechanism for high mortality in northern leopard frogs seen here. As such, future work would benefit from histological studies on the liver of frogs exposed to MC-LR.

The difference between the two amphibian species may be due to the fact that the bullfrogs were wild-caught whereas the leopard frogs were lab-reared if the bullfrog tadpoles which we collected represented relatively hardy individuals more resistant to environmental perturbations. It could also be due to the life history traits associated with these two amphibians. Bullfrogs are longer-lived compared to northern leopard frogs are short-lived, and it is possible that longer-lived species invest more in immune defences against parasites rather than short-lived species which are thought to rely more on behavioural means of defense (Koprivnikar et al., 2014). Another possible explanation is mass. Bullfrog tadpoles at the same stage are much larger than northern leopard frogs, so MC-LR might have been absorbed much more in the latter to cause harmful effects. Some studies (Schuytema \& Nebeker, 1998; Lannoo, 2005) have also found that bullfrogs generally suffer fewer ill effects of contaminant exposure than other amphibian species for whatever reason.

Further work should focus on taking a measure of larval tadpole blood profiles when exposed to MC-LR and trematodes to examine whether MC-LR could impair immune system function or increase stress levels. A combination of factors should also be examined, such as temperature changes in the presence of MC-LR, as it was shown that MC-LR is more easily taken up in higher temperatures (Zhang et al., 2009). Other amphibian species should also be examined as it was shown that there could be a stronger negative effects on some species. Lastly, larger concentrations of MC-LR should be examined, as toxic cyanobacterial blooms are an increasing problem (Paerl \& Huisman, 2009) and in recent years, MC-LR has been found in record concentrations (Michalak et al., 2013). 
Studying the effect of MC-LR on amphibians is important because diseases, including trematodes are a key component in amphibian decline (Daszak et al., 2003). Thus, if a toxin has the capacity to increase amphibian susceptibility to infection, it can contribute to their global decline, and here it was shown that MC-LR does increase tadpole susceptibility to infection. Just as in amphibians, it is possible that MC-LR also has the same effect on other organisms which commonly come in contact with it. Thus, the promotion of algal blooms could play a role in increased parasitism in aquatic ecosystems on a larger scale, especially because toxic blooms are getting worse (Paerl \& Huisman, 2009). 


\section{References:}

Beebee, T.J. and Griffiths, R.A., (2005). The amphibian decline crisis: a watershed for conservation biology? Biological Conservation, 125, 271-285.

Chernoff, N., Hunter III, E. S., Hall, L. L., Rosen, M. B., Brownie, C. F., Malarkey, D., Herkovits, J. (2002). Lack of teratogenicity of microcystin-LR in the mouse and toad. Journal of Applied Toxicology, 22, 13-17.

Codd, G. A. (2000). Cyanobacterial toxins, the perception of water quality, and the prioritisation of eutrophication control. Ecological Engineering, 16, 51-60.

Coors, A., Decaestecker, E., Jansen, M., \& De Meester, L. (2008). Pesticide exposure strongly enhances parasite virulence in an invertebrate host model. Oikos, 117, 1840-1846.

Daly, E. W., \& Johnson, P. T. J. (2011). Beyond immunity: Quantifying the effects of host antiparasite behavior on parasite transmission. Oecologia, 165, 1043-1050.

Daszak, P., Cunningham, A. A., \& Hyatt, A. D. (2003). Infectious disease and amphibian population declines. Diversity and Distributions, 9, 141-150.

Delaney, J. M., \& Wilkins, R. M. (1995). Toxicity of microcystin-LR, isolated from Microcystis aeruginosa, against various insect species. Toxicon, 33, 771-778.

Dietrich, D., \& Hoeger, S. (2005). Guidance values for microcystins in water and cyanobacterial supplement products (blue-green algal supplements): A reasonable or misguided approach? Toxicology and Applied Pharmacology, 203, 273-289.

Eriksson, J. E., Grönberg, L., Nygård, S., Slotte, J. P., \& Meriluoto, J. A. O. (1990). Hepatocellular uptake of 3H-dihydromicrocystin-LR, a cyclic peptide toxin. $B B A$ Biomembranes, 1025, 60-66. 
Fischer, W. J., \& Dietrich, D. R. (2000). Toxicity of the cyanobacterial cyclic heptapeptide toxins microcystin-LR and -RR in early life-stages of the African clawed frog (Xenopus laevis). Aquatic Toxicology, 49, 189-198.

Fong, N. M., Jensen, T. C., Shah, A. S., Parekh, N. N., Saltiel, A. R., \& Brady, M. J. (2000). Identification of binding sites on protein targeting to glycogen for enzymes glycogen metabolism. Journal of Biological Chemistry, 275, 35034-35039.

Galloway, T. S., \& Depledge, M. H. (2001). Immunotoxicity in invertebrates: Measurement and ecotoxicological relevance. Ecotoxicology, 10, 5-23.

Gérard, C., Carpentier, A., \& Paillisson, J. (2008). Long-term dynamics and community structure of freshwater gastropods exposed to parasitism and other environmental stressors. Freshwater Biology, 53, 470-484.

Gosner, K.L., (1960). A simplified table for staging anuran embryos and larvae with notes on identification. Herpetologica, 16, 183-190.

Graham, J. L., \& Jones, J. R. (2009). Microcystin in Missouri reservoirs. Lake and Reservoir Management, 25, 253-263.

http://apps.who.int/iris/bitstream/10665/44584/1/9789241548151_eng.pdf http://www.hc-sc.gc.ca/ewh-semt/pubs/water-eau/sum_guide-res_recom/index-eng.php Jones, G. J., \& Orr, P. T. (1994). Release and degradation of microcystin following algicide treatment of a Microcystis aeruginosa bloom in a recreational lake, as determined by HPLC and protein phosphatase inhibition assay. Water Research, 28, 871-876.

Johnson, P. T. J., Lunde, K. B., Ritchie, E. G., Reaser, J. K., \& Launer, A. E. (2001). Morphological abnormality patterns in a California amphibian community. Herpetologica, 57, $336-352$. 
Kiesecker, J. M. (2002). Synergism between trematode infection and pesticide exposure: A link to amphibian limb deformities in nature? Proceedings of the National Academy of Sciences of the United States of America, 99, 9900-9904.

Koprivnikar, J. (2010). Interactions of environmental stressors impact survival and development of parasitized larval amphibians. Ecological Applications, 20, 2263-2272.

Koprivnikar, J., Forbes, M.R. and Baker, R.L., (2006). On the efficacy of anti-parasite behaviour: a case study of tadpole susceptibility to cercariae of Echinostoma trivolvis. Canadian Journal of Zoology, 84, 1623-1629.

Koprivnikar, J., Redfern, J. C., \& Mazier, H. L. (2014). Variation in anti-parasite behaviour and infection among larval amphibian species. Oecologia, 174, 1179-1185.

Kotak, B. G., \& Zurawell, R. W. (2007). Cyanobacterial toxins in Canadian freshwaters: A review. Lake and Reservoir Management, 23, 109-122.

LaFonte, B. E., \& Johnson, P. T. J. (2013). Experimental infection dynamics: Using immunosuppression and in vivo parasite tracking to understand host resistance in an amphibiantrematode system. Journal of Experimental Biology, 216, 3700-3708.

Lahti, K., Rapala, J., Färdig, M., Niemelä, M., \& Sivonen, K. (1997). Persistence of cyanobacterial hepatotoxin, microcystin-LR in particulate material and dissolved in lake water. Water Research, 31, 1005-1012.

Lance, E., Josso, C., Dietrich, D., Ernst, B., Paty, C., Senger, F., Gérard, C. (2010). Histopathology and microcystin distribution in Lymnaea stagnalis (Gastropoda) following toxic cyanobacterial or dissolved microcystin-LR exposure. Aquatic Toxicology, 98, 211-220. Lannoo, M.J., (2005). Amphibian declines: the conservation status of United States species. University of California Press. 1094 pgs. 
Laurén-Määttä, C., Hietala, J., Reinikainen, M., \& Walls, M. (1995). Do Microcystis aeruginosa toxins accumulate in the food web: A laboratory study. Hydrobiologia, 304, 23-27.

Liu, W., Shen, Y., \& Ding, J. (2003). Protein phosphatase 2A: Its structure, function and activity regulation. Acta Biochimica Et Biophysica Sinica, 35, 105-112.

MacKintosh, C., Beattie, K. A., Klumpp, S., Cohen, P., \& Codd, G. A. (1990). Cyanobacterial microcystin-LR is a potent and specific inhibitor of protein phosphatases 1 and $2 \mathrm{~A}$ from both mammals and higher plants. FEBS Letters, 264, 187-192.

Michalak, A. M., Anderson, E. J., Beletsky, D., Boland, S., Bosch, N. S., Bridgeman, T. B., Zagorski, M. A. (2013). Record-setting algal bloom in lake Erie caused by agricultural and meteorological trends consistent with expected future conditions. Proceedings of the National Academy of Sciences of the United States of America, 110, 6448-6452.

Munusamy, T., Hu, Y., \& Lee, J. (2012). Adsorption and photodegradation of microcystin-LR onto sediments collected from reservoirs and rivers in Taiwan: A laboratory study to investigate the fate, transfer, and degradation of microcystin-LR. Environmental Science and Pollution Research, 19, 2390-2399.

Orihel, D. M., Bird, D. F., Brylinsky, M., Chen, H., Donald, D. B., Huang, D. Y., Vinebrooke, R. D. (2012). High microcystin concentrations occur only at low nitrogen-to-phosphorus ratios in nutrient-rich Canadian lakes. Canadian Journal of Fisheries and Aquatic Sciences, 69, 14571462.

Paerl, H. W., \& Huisman, J. (2009). Climate change: A catalyst for global expansion of harmful cyanobacterial blooms. Environmental Microbiology Reports, 1, 27-37. 
Perri, K. A., Sullivan, J. M., \& Boyer, G. L. (2015). Harmful algal blooms in Sodus Bay, Lake Ontario: A comparison of nutrients, marina presence, and cyanobacterial toxins. Journal of Great Lakes Research, 41, 326-337.

Schotthoefer, A.M., Cole, R.A. and Beasley, V.R., (2003). Relationship of tadpole stage to location of echinostome cercariae encystment and the consequences for tadpole survival. Journal of Parasitology, 89, 475-482.

Schuytema, G.S. and Nebeker, A.V., (1998). Comparative toxicity of diuron on survival and growth of Pacific treefrog, bullfrog, red-legged frog, and African clawed frog embryos and tadpoles. Archives of Environmental Contamination and Toxicology, 34, 370-376.

Steffen, M. M., Belisle, B. S., Watson, S. B., Boyer, G. L., \& Wilhelm, S. W. (2014). Status, causes and controls of cyanobacterial blooms in Lake Erie. Journal of Great Lakes Research, 40, $215-225$.

Tournebize, R., Andersen, S. S. L., Verde, F., Dorée, M., Karsenti, E., \& Hyman, A. A. (1997). Distinct roles of PP1 and PP2A-like phosphatases in control of microtubule dynamics during mitosis. EMBO Journal, 16, 5537-5549.

Urrutia-Cordero, P., Agha, R., Cirés, S., Lezcano, M. T., Sánchez-Contreras, M., Waara, K. Quesada, A. (2013). Effects of harmful cyanobacteria on the freshwater pathogenic free-living amoeba Acanthamoeba castellanii. Aquatic Toxicology, 130, 9-17.

Waajen, G. W. A. M., Faassen, E. J., \& Lürling, M. (2014). Eutrophic urban ponds suffer from cyanobacterial blooms: Dutch examples. Environmental Science and Pollution Research, 21, 9983-9994. 
Williams, C. D., Aubel, M. T., Chapman, A. D., \& D'Aiuto, P. E. (2007). Identification of cyanobacterial toxins in Florida's freshwater systems. Lake and Reservoir Management, 23, 144152.

Zambrano, F., \& Canelo, E. (1996). Effects of microcystin-LR on the partial reactions of the Na+-K+ pump of the gill of carp (Cyprinus carpio linneo). Toxicon, 34, 451-458.

Zhang, D., Xie, P., Liu, Y., Chen, J., \& Wen, Z. (2009). Spatial and temporal variations of microcystins in hepatopancreas of a freshwater snail from Lake Taihu. Ecotoxicology and Environmental Safety, 72, 466-472.

Ziková, A., Lorenz, C., Lutz, I., Pflugmacher, S., \& Kloas, W. (2013). Physiological responses of Xenopus laevis tadpoles exposed to cyanobacterial biomass containing microcystinLR. Aquatic Toxicology, 128, 25-33.

Zurawell, R. W., Chen, H., Burke, J. M., \& Prepas, E. E. (2005). Hepatotoxic cyanobacteria: A review of the biological importance of microcystins in freshwater environments. Journal of Toxicology and Environmental Health - Part B: Critical Reviews, 8, 1-37. 


\section{CHAPTER 3: EFFECT OF CYANOBACTERIAL TOXINS ON A PARASITE INFECTIOUS STAGE}

\section{Introduction:}

The life cycles of many parasites are complex, utilizing multiple hosts and involving one or two free-living infectious stages. These free-living stages are at the mercy of the environment and susceptible to the same abiotic and biotic stressors as true free-living organisms (Pietrock \& Marcogliese, 2003; Thieltges et al., 2008). This can have important implications for their infectivity and transmission success. As such, it is essential to study how parasites themselves might be affected by environmental conditions, not just hosts, to understand the net outcome for host-parasite dynamics.

The life cycle of trematode (Phylum Platyhelminthes) parasites is a prime example of the potential for environmental conditions to affect transmission - see Chapter 1 for a detailed description. Upon emergence from the aquatic first intermediate gastropod host where they develop, free-swimming cercariae must seek out the next host to infect and therein lies the challenge. In addition to the barrier posed by the structural complexity of the environment (Prinz et al., 2009; Welsh et al., 2014), chemicals are even more important. Natural or anthropogenic fluctuations in parameters such as water temperature, salts, water hardness, and $\mathrm{pH}$ are all known to harm cercariae, with detrimental effects increasing with extremes values (e.g. Morley et al., 2003; Pietrock and Marcogliese 2003).

Natural variables can negatively affect cercariae, but anthropogenic pollutants are becoming increasingly common. Koprivnikar et al. (2006) tested the cercariae of different trematode species and found that the pesticide atrazine can increase the mortality of cercariae and decrease their activity and infectivity. Other studies that also examined pesticides found 
similar effects (Griggs \& Belden, 2008). Heavy metals, fertilizers, hydrocarbons, and sewage sludge have also been found to be detrimental to cercariae (Morley et al., 2003). Many of these pollutants were found not only to reduce survival, but also to reduce penetration, maturation and activity of trematodes (MacKenzie, 1995; Morley et al., 2003), often within the first few hours where cercariae are most infective. One study also found a reduction in the horizontal swimming rate of cercariae from polluted sites (Cross et al., 2001). This is important because many cercariae live for only approximately 24 hours and remain infective for only a portion of that, typically 8 hours (McCarthy, 1999). Thus, if a substance in the environment harms cercariae, not only can their longevity be affected, but also their activity and infectivity, both potentially resulting in lower host-finding success and reduced transmission. However, different trematode species may tolerate pollutants and other stressors more than others and it is thus important to examine various different species. Substances toxic to parasites need not only be anthropogenic in origin. For instance, invasive algae may have the potential to release chemicals toxic to cercariae (Bartoli \& Boudouresque, 1997), and indeed, an exudate from a plant was found to have a cercaricidal effect (Warren \& Peters, 1968).

Although industrial or agricultural effluent can be directly toxic, the indirect downstream effects can be just as important. For example, nutrient-overloading in waterbodies causes eutrophication, which can trigger explosive growth of cyanobacteria. Many cyanobacterial strains can be toxic through the production of compounds called microcystins, which are known hepatotoxins for many animals (Zurawell et al., 2005). Microcystins can cause massive fish kills during algal blooms, partially because they inhibit the ATPase activity of the $\mathrm{Na}^{+} / \mathrm{K}^{+}$pump in the gills of carp (Zambrano \& Canelo, 1996), causing loss of gill function. Microcystins can also cause a loss of cytoskeletal structure, promote tumour growth (Codd, 2000) and can cause severe 
liver damage (Zurawell et al., 2005). This toxic effect is manifested mainly through the inhibition of serine/threonine phosphatases - protein phosphatase-1 (PP-1) and protein phosphatase-2A (MacKintosh et al., 1990). The binding can be irreversible (Dietrich \& Hoeger, 2005). As outlined in Chapters 1 and 2, cyanobacterial blooms are common and a worldwide problem, varying in size and severity. Concentrations in the water can be less than $1 \mu \mathrm{g} / \mathrm{L}$ to over $5000 \mu \mathrm{g} / \mathrm{L}$ (Williams et al., 2007) with the most common form of microcystin being microcystinLR (MC-LR) (Waajen et al., 2014). As a wide-spread PP-1 and PP-2A inhibitor in freshwater systems, it is likely that MC-LR has a detrimental effect on parasites.

Microcystins are harmful for many aquatic organisms, including the first and second intermediate hosts of trematodes such as snails and amphibians (Zurawell et al., 2005). Because I found in Chapter 2 that MC-LR can increase tadpole susceptibility to infection, it is important to examine whether it has any effect on cercariae too. Notably, these compounds can also decrease the activity of small animals without livers, such as protists, zooplankton, and certain macroinvertebrates (Zurawell et al., 2005). There is thus clear potential for microcystins to affect parasite free-living stages; however, their effects have not been examined on any trematode life stage. Studying the effects of MC-LR on the longevity and activity of cercariae is important because the cyanobacterial problem is getting worse (Paerl \& Huisman, 2009) and any negative effects could influence host-parasite dynamics. If MC-LR has a differential effect on the cercariae of different trematode species found in a given community, it could cause a shift in the species abundance and richness where more resistant species remain and the more susceptible species perish.

Trematodes infecting amphibians can be quite pathogenic (Johnson et al., 2001; Koprivnikar et al., 2012) so it is important to understand if toxins can affect the parasite stage 
which infects them, especially since I found that MC-LR can increase amphibian susceptibility. The net effect of host and parasite effects can even be neutral. For example, Koprivnikar et al. (2007) found that the pesticide atrazine both increased tadpole susceptibility to infection by a trematode but also reduced cercarial infection success such that there was no net effect of the contaminant. As such, the goals of this study were to examine the effect of MC-LR on the activity and longevity of various cercariae species. I hypothesized that MC-LR would reduce cercariae activity and longevity.

\section{Materials and Methods}

\section{Trematode acquisition}

Several hundred aquatic snails (Helisoma trivolvis) were collected from various ponds near Guelph, Ontario (see Chapter 2). Collected snails were screened for trematode infection by placement in a Petri dish with treated water and a piece of spinach. The snails were exposed to a $60 \mathrm{~W}$ incandescent lamp for 1 hour to stimulate the release of cercariae. Trematode cercariae were identified with standard keys (Schell, 1970; Schell, 1985) using a compound microscope and infected snails were separated from uninfected snails, as well as grouped by their infection type. Infected snails were kept in communal tubs with treated water at a density of 10 snails per tub and were fed raw spinach ad libitum. Four trematode types (genera) were identified: Echinostoma trivolvis, an unidentified strigeid-type cercariae, an unidentified armatae-type cercariae, and Trichobilharzia sp.

Experimental procedure

The same stock and working solutions were used from Chapter 2 (see for preparation details). A working solution of $10 \mu \mathrm{g} / \mathrm{L}$ MC-LR was prepared by pipetting $100 \mathrm{~mL}$ of the 100 $\mu \mathrm{g} / \mathrm{L}$ working solution into $900 \mathrm{~mL}$ of water. The MC-LR concentrations were chosen because 
they represent a common low MC-LR concentration $(10 \mu \mathrm{g} / \mathrm{L})$ and a common medium-high MCLR level (100 $\mu \mathrm{g} / \mathrm{L})$ found in nature (Williams et al., 2007).

When needed, cercariae were obtained by placing infected snails in Petri dishes of water under a lamp for one hour during mid-day. The cercariae were removed from Petri dishes using a dissection scope and a standard plastic pipette. After mixing cercariae of a given genus in a common Petri dish to randomize variation in age and genotype, actively swimming cercariae were transferred into single wells of a 96 well tissue culture plate (i.e. one cercariae/well) containing $1 \mathrm{~mL}$ of the treatment. No cercariae were older than 3 hours. Because MC-LR binds to most plastics, we used specialized cell-well plates made of polyethylene glycol (PEG). Each genus of trematode was designated 20 plates in total, with 5 plates for each treatment (control, solvent control, $10 \mu \mathrm{g} / \mathrm{L}$ MC-LR, and $100 \mu \mathrm{g} / \mathrm{L}$ MC-LR). Within each plate, 5 wells were chosen as a replicate such that each genera had a sample size of 25. Plates of cercariae were examined in random order under a dissecting scope every two hours $(2,4,6,8)$ and then at $24 \mathrm{~h}$ (usual maximum life span). The active swimming activity (yes or no) and survival (dead or alive) were recorded for each individual at the designated time points. Cercariae were considered dead once they no longer responded to stimulus by a probe. The experiments for each genus were carried out on separate days.

\section{Data analysis}

The analyses was done in SPSS 23.0, using Generalized Linear Mixed Models (GLMM) because I had repeated measurements for each individual and also wanted to look for an interaction of treatment and time. The dependent data (activity and survival, respectively) were given a binomial distribution with a logit link function. The fixed effects were the treatment, time, and the interaction of time and treatment, with well number and plate number entered as 
random effects. Non-significant interactions and fixed effects were dropped and models re-run to obtain a final model. Each genus was analyzed separately. Solutions were analyzed for MC-LR concentrations (see results in Chapter 2).

\section{Results}

Mortality

The overall model for E. trivolvis mortality was significant $\left(\mathrm{F}_{7,472}=16.459, \mathrm{P}<0.001\right)$ but only included time (Fig. 3.1). The overall model for Trichobilharzia sp. mortality was significant $\left(\mathrm{F}_{7,487}=15.248, \mathrm{P}<0.001\right)$; however, time was also the only fixed effect that was retained (Fig. 3.2). Similarly, the overall model for armatae-type cercarial mortality was significant $\left(\mathrm{F}_{7,467}=17.758, \mathrm{P}<0.001\right)$ but only included time (Fig. 3.3). In contrast, the overall model for strigeid-type mortality was significant $\left(\mathrm{F}_{7,482}=16.443, \mathrm{P}<0.001\right)$ and included both time $(\mathrm{P}<0.001)$ and treatment $(\mathrm{P}<0.001)$ as survival was enhanced in solutions of MC-LR (Fig. 3.4). Pairwise comparisons revealed a significant difference between the control and $100 \mu \mathrm{g} / \mathrm{L}(\mathrm{P}$ $=0.002)$, between the solvent control and $100 \mu \mathrm{g} / \mathrm{L}(\mathrm{P}=0.013)$, and between $10 \mu \mathrm{g} / \mathrm{L}$ and 100 $\mu \mathrm{g} / \mathrm{L}(\mathrm{P}=0.029)$. For all genera, survivorship decreased with time.

Activity

The overall model for E. trivolvis activity was significant $\left(\mathrm{F}_{7,472}=14.838, \mathrm{P}<0.001\right)$ but only included time. The effect of treatment on strigeid-type cercarial activity in the overall model was significant $\left(\mathrm{F}_{7,482}=18.095, \mathrm{P}<0.001\right)$ and only retained time as well. However, there was a weak tendency for MC-LR exposure to have a positive effect $(\mathrm{P}=0.116)$ as there was a significant difference in cercariae from the control versus those exposed to $100 \mu \mathrm{g} / \mathrm{L}(\mathrm{P}=0.017)$. The overall model for Trichobilharzia sp. activity was significant $\left(\mathrm{F}_{7,487}=13.953, \mathrm{P}<0.001\right)$ and only included time. Lastly, the overall model for armatae-type cercariae activity was also 
significant $\left(\mathrm{F}_{7,467}=10.594, \mathrm{P}<0.001\right)$, and again only retained time $(\mathrm{P}<0.001)$. As for mortality, the passage of time always had a negative effect. 
Figure 3.1: The Effect of MC-LR on E. trivolvis cercariae survival and activity as the sum of cercariae that were alive or active at each time point in each treatment.
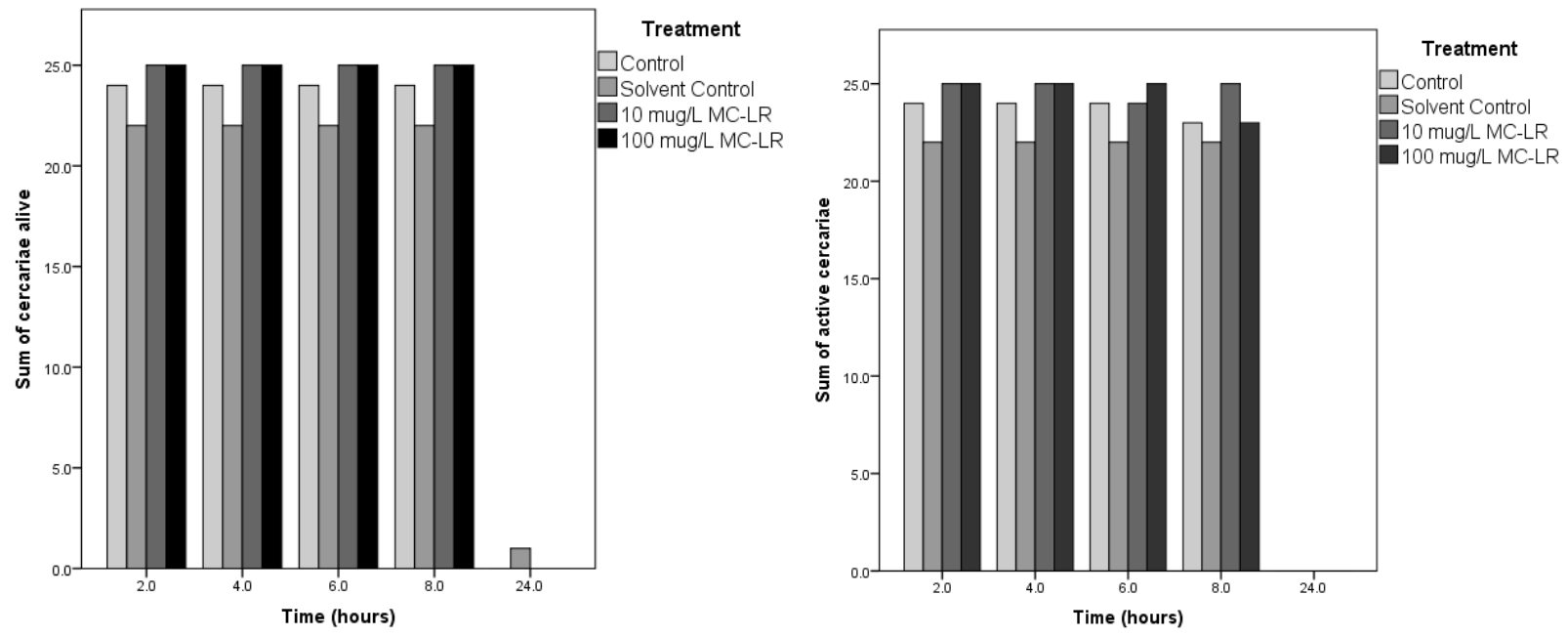
Figure 3.2: The effect of MCLR treatment on Trichobilharzia sp. cercariae survival and activity as the sum of cercariae that were alive or active at each time point.
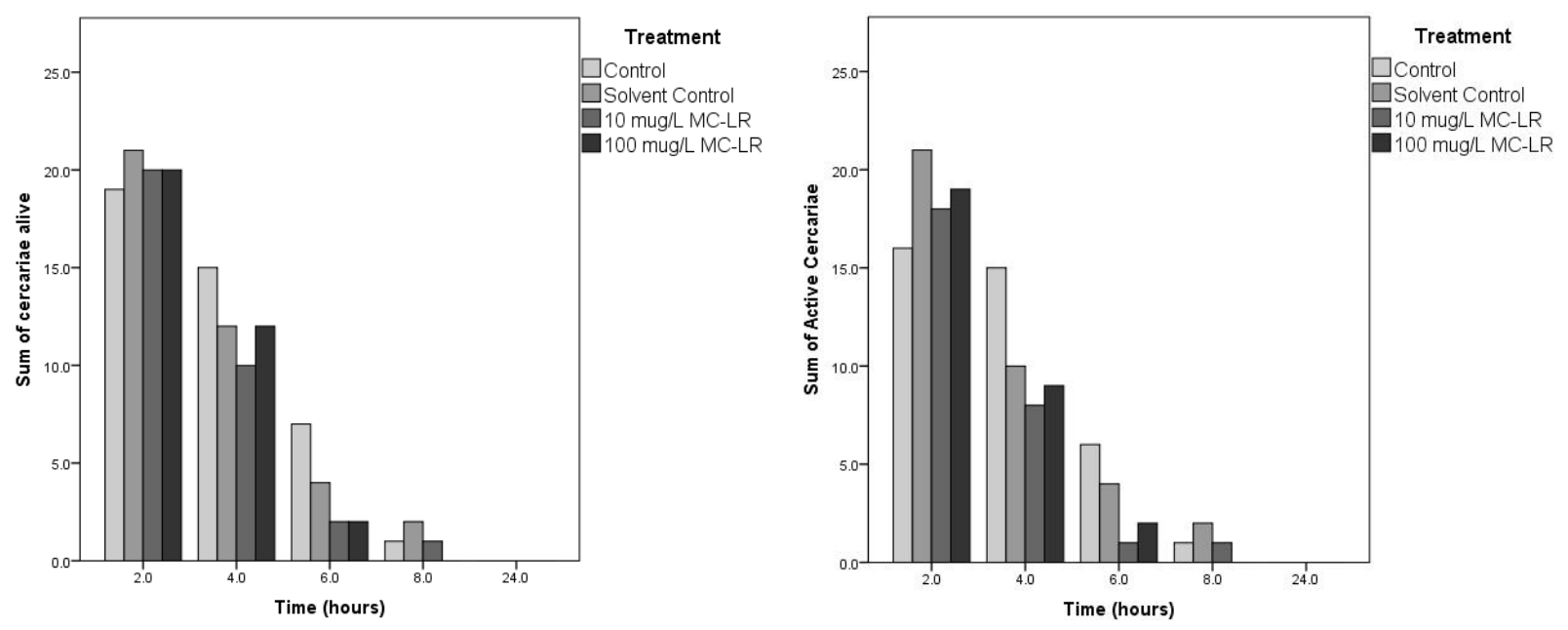
Figure 3.3: The effect of MC-LR treatment on armatae-type cercariae survival and activity as the sum of cercariae that were alive or active at each time point.
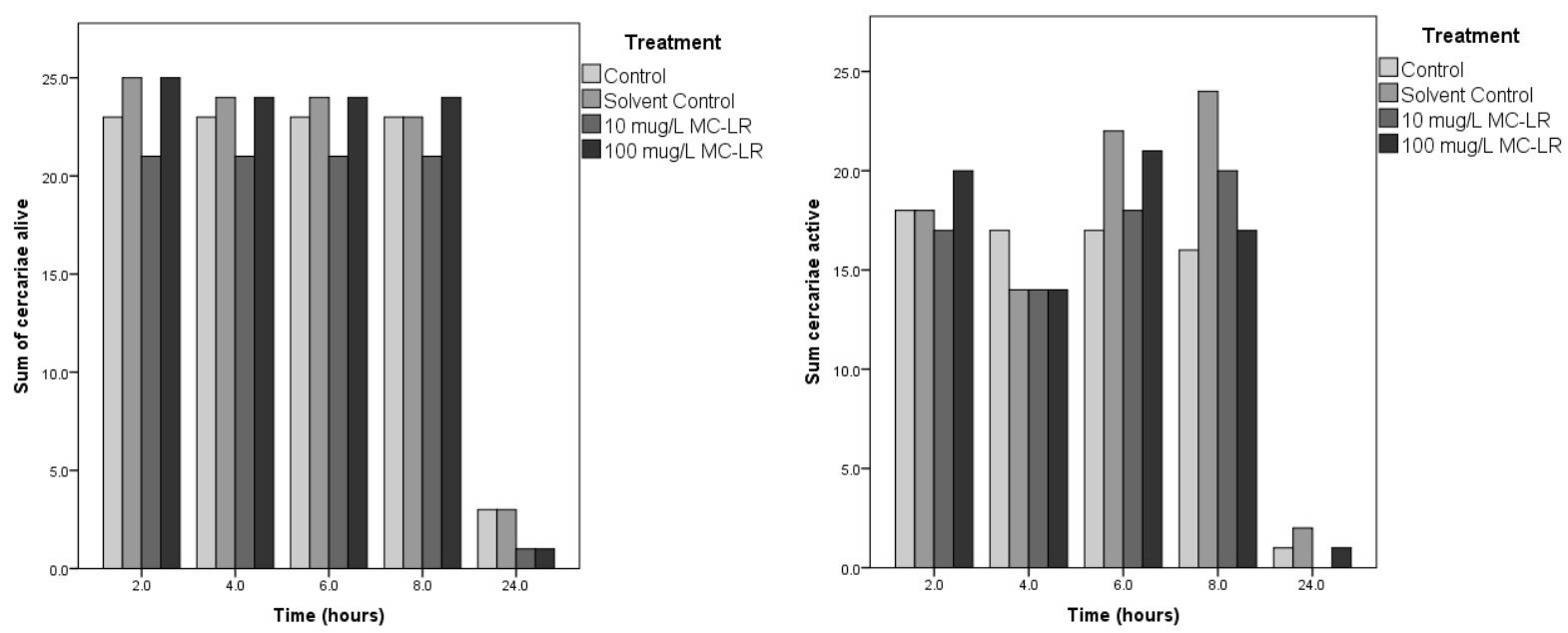
Figure 3.4: The effect of MC-LR treatment on strigeid-type cercariae survival and activity as the sum of cercariae that were alive or active at each time point.
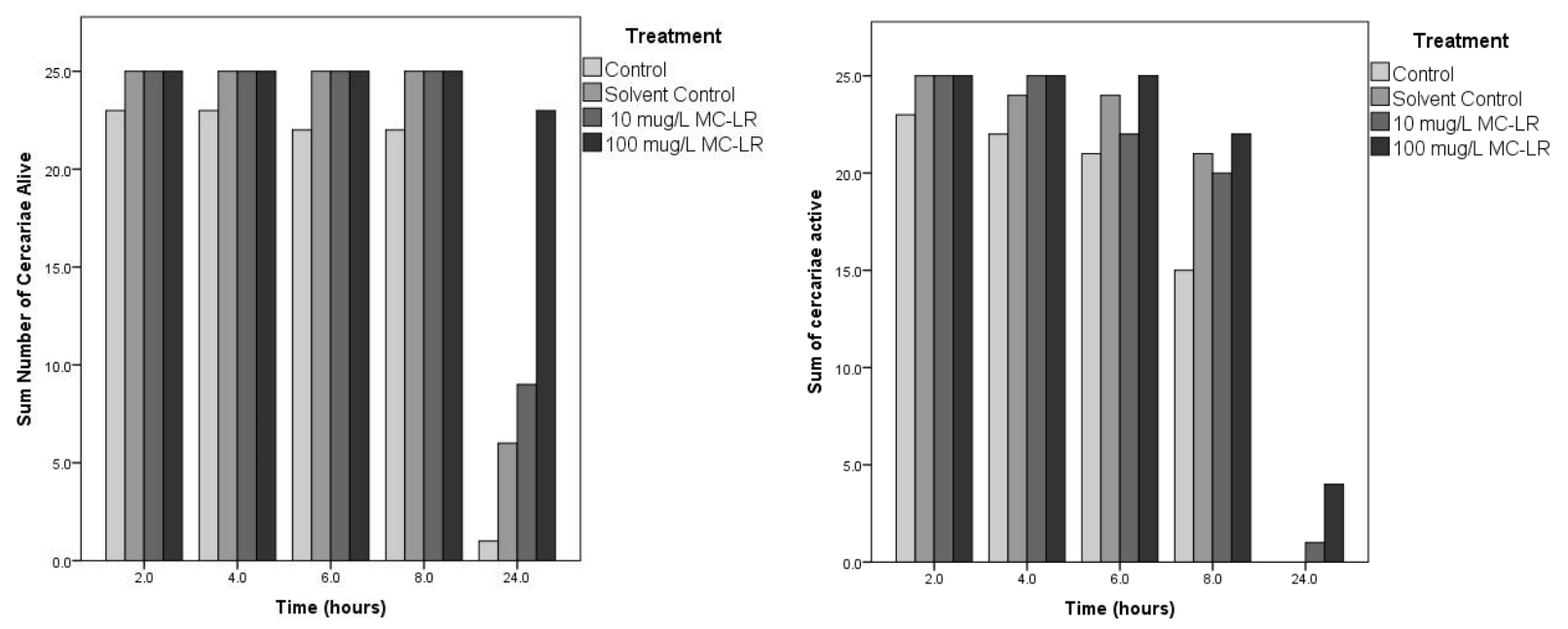


\section{Discussion}

The widespread cyanobacterial toxin, MC-LR, was found to have varying effects on cercariae of different species. Of the four studied species, one (strigeid-type) experienced increased survivorship at the highest MC-LR concentration $(100 \mu \mathrm{g} / \mathrm{L})$. A trend for increased activity at the highest concentration was also seen for this species. The highest concentration of MC-LR $(100 \mu \mathrm{g} / \mathrm{L})$ in this study reflects natural dissolved MC-LR concentrations in moderate blooms (refer to Chapter 2). Importantly, cercarial longevity was increased beyond the typical 24 hours. Additionally, cercarial activity was drastically increased by this concentration within the first 8 hours, which is the time when cercariae are typically most infective (McCarthy, 1999), given that the effect of MC-LR was not dependent on time elapsed. This suggests that at environmentally relevant concentrations, cyanobacterial blooms and their toxins have the capacity to promote cercariae survival and/or increase their activity, thereby promoting transmission to second intermediate hosts such as amphibians. However, in very severe blooms, MC-LR concentrations can be much higher than $100 \mu \mathrm{g} / \mathrm{L}$ (Kotak \& Zurawell, 2007), thus it is possible that extreme MC-LR concentrations could lead to mortality, as very high toxin concentrations are sometimes needed to elicit a negative response in cercariae (Pietrock \& Marcogliese, 2003). High MC-LR concentrations could cause mortality or a loss of activity, leaving only a small window of time for cercariae to infect their host. Interestingly, the low concentration of MC-LR, $10 \mu \mathrm{g} / \mathrm{L}$, had no effect on any parameter of any species, suggesting that only more severe blooms could have an effect on cercariae.

The effects seem to be species-specific, suggesting a differential effect of MC-LR on cercariae in the environment. If some trematode species are affected more than others, it could lead to a shift in parasite species abundance and richness, with the species responding positively 
to the toxin increasing in number due to a potential increase in transmission, whereas the less susceptible species would become less common. The manner in which MC-LR affects organisms has been well studied (Zurawell et al., 2005), but has never been studied in trematodes. MC-LR is a potentially irreversible (Dietrich \& Hoeger, 2005) inhibitor of the serine/threonine phosphotases protein phosphotase-1 and protein phosphotase-2A (PP-1 and PP-2A) (MacKintosh et al., 1990). Protein phosphatases are critical in biochemical pathways. PP-1 plays an important part in regulating various cellular functions such as the proper functioning of membrane receptors and channels, the cell cycle, mitosis, controls microtubule dynamics, as well as regulating glycogen metabolism (Tournebize et al., 1997; Fong et al., 2000). PP-2A plays a role in the cell cycle and regulates microtubule length in mitosis (Tournebize et al., 1997) and also plays a role in signaling pathways and cell differentiation (Liu et al., 2003). Thus, inhibiting PP1 and PP-2A can have drastic effects on cellular structure, replication and function. So far, the bile-acid transporter found in the liver and intestines of higher animals has been identified as the entry point of MC-LR (Eriksson et al., 1990). However, Platyhelminthes do not possess a liver or intestine, but they have a caecum and it is possible that this is where active transport of MC-LR occurs. Although MC-LR has been found to be unable to cross cell membranes very well (Eriksson et al., 1990), it is possible that it gains entrance into cercariae through openings in the cephalic region, excretory pores, or other openings.

Once inside, protein phosphotase inhibition can have many detrimental downstream effects. MC-LR causes a loss of cytoskeletal structure in affected cells and is a tumour promoter (Codd, 2000). Its effect on the cytoskeleton has the potential to cause cell death and tissue necrosis (Zurawell et al., 2005). The positive effects of MC-LR could be due to the involvement of PP-1 in glycogen metabolism (Fong et al., 2000). Since cercariae rely on glycogen reserves 
for survival (McCarthy, 1999), any disruptions with their glycogen reserves could directly increase or decrease their survival and/or activity. Further, protein phosphotase inhibition by MC-LR was shown to have a downstream effect on ion balance in organisms (Zurawell et al., 2005). For example, in fish gills, there was a decrease in the function of an ATPase regulating the function of the $\mathrm{Na}^{+} / \mathrm{K}^{+}$pump, causing death (Zambrano \& Canelo, 1996). If the downstream effect of protein phosphotase inhibition by MC-LR can have a similar down-regulating effect on $\mathrm{Ca}^{2+}$ channels, it could potentially decrease penetration success in cercariae because $\mathrm{Ca}^{2+}$ channels are important for cercarial penetration into hosts (Fusco et al., 1991), as well as the process in penetration whereby cercariae lose their tail (Matsumura et al., 1991) and cercarial penetration success was not tested here. Any such effects might cause a shift in energy use by cercariae, directly affecting their activity and lifespan. Thus, although sub-lethal concentrations of MC-LR $(10 \mu \mathrm{g} / \mathrm{L})$ had no apparent effect on cercarial activity or longevity, detrimental effects could still occur. Additional studies examining the effect of MC-LR on the ability of cercariae to infect hosts will be needed.

Further studies also need to be performed on accumulation of MC-LR in host tissues and whether this can harm the cysts (metacercariae) formed within the host. For example, cercariae which seek to encyst in the liver or intestines could be disrupted because this is where MC-LR can accumulate (Zurawell et al., 2005; Lance et al., 2010), and it has been shown that other pollutants, such as pesticides and heavy metals, can interfere with encystment (Morley et al., 2003). Amphibian kidneys are home to E. trivolvis, and because kidneys can in fact be indirectly damaged by MC-LR (Zurawell et al., 2005), this may potentially interfere with E. trivolvis encystment. In the gastropod first intermediate hosts where cercariae are produced, the miracidia stage that infects snails first migrates to the gonadic tissues of snails where MC-LR was found to 
accumulate (Lance et al., 2010). There, it could potentially interfere with the establishment of the structures used for asexual reproduction and cercariae development (sporocysts and rediae). Work on the effects of MC-LR on trematodes is in its infancy, requiring much further study to get a better picture of how exactly this toxin can affect not only trematodes, but also their hosts and transmission pathways. Given the important effects of trematodes on many hosts, such information is critical to predict how cyanobacterial booms might influence infectious diseases. 


\section{References:}

Bartoli, P., \& Boudouresque, C. (1997). Transmission failure of parasites (Digenea) in sites colonized by the recently introduced invasive alga Caulerpa taxifolia. Marine Ecology Progress Series, 154, 253-260.

Codd, G. A. (2000). Cyanobacterial toxins, the perception of water quality, and the prioritisation of eutrophication control. Ecological Engineering, 16, 51-60.

Cross, M. A., Irwin, S. W. B., \& Fitzpatrick, S. M. (2001). Effects of heavy metal pollution on swimming and longevity in cercariae of Cryptocotyle lingua (Digenea: Heterophyidae). Parasitology, 123, 499-507.

Dietrich, D., \& Hoeger, S. (2005). Guidance values for microcystins in water and cyanobacterial supplement products (blue-green algal supplements): A reasonable or misguided approach? Toxicology and Applied Pharmacology, 203, 273-289.

Eriksson, J. E., Grönberg, L., Nygård, S., Slotte, J. P., \& Meriluoto, J. A. O. (1990). Hepatocellular uptake of $3 \mathrm{H}$-dihydromicrocystin-LR, a cyclic peptide toxin. $B B A$ Biomembranes, 1025, 60-66.

Fusco, A. C., Salafsky, B., Vanderkooi, G., \& Shibuya, T. (1991). Schistosoma mansoni: The role of calcium in the stimulation of cercarial proteinase release. Journal of Parasitology, 77, 649-657.

Fong, N. M., Jensen, T. C., Shah, A. S., Parekh, N. N., Saltiel, A. R., \& Brady, M. J. (2000). Identification of binding sites on protein targeting to glycogen for enzymes glycogen metabolism. Journal of Biological Chemistry, 275, 35034-35039. 
Griggs, J.L. and Belden, L.K., (2008). Effects of atrazine and metolachlor on the survivorship and infectivity of Echinostoma trivolvis trematode cercariae. Archives of Environmental Contamination and Toxicology, 54, 195-202.

Johnson, P. T. J., Lunde, K. B., Ritchie, E. G., Reaser, J. K., \& Launer, A. E. (2001). Morphological abnormality patterns in a california amphibian community. Herpetologica, 57, $336-352$.

Koprivnikar, J., Forbes, M.R. and Baker, R.L., (2007). Contaminant effects on host-parasite interactions: atrazine, frogs, and trematodes. Environmental Toxicology and Chemistry, 26, 2166-2170

Koprivnikar, J., Marcogliese, D.J., Rohr, J.R., Orlofske, S.A., Raffel, T.R. and Johnson, P.T., (2012). Macroparasite infections of amphibians: what can they tell us? EcoHealth, 9, 342360.

Koprivnikar, J., Forbes, M. R., \& Baker, R. L. (2007). Contaminant effects on host-parasite interactions: Atrazine, frogs, and trematodes. Environmental Toxicology and Chemistry, 26, 2166-2170.

Kotak, B. G., \& Zurawell, R. W. (2007). Cyanobacterial toxins in Canadian freshwaters: A review. Lake and Reservoir Management, 23, 109-122.

Lance, E., Josso, C., Dietrich, D., Ernst, B., Paty, C., Senger, F., Gérard, C. (2010). Histopathology and microcystin distribution in Lymnaea stagnalis (Gastropoda) following toxic cyanobacterial or dissolved microcystin-LR exposure. Aquatic Toxicology, 98, 211-220. Liu, W.., Shen, Y., \& Ding, J. (2003). Protein phosphatase 2A: Its structure, function and activity regulation. Acta Biochimica Et Biophysica Sinica, 35, 105-112.

MacKintosh, C., Beattie, K. A., Klumpp, S., Cohen, P., \& Codd, G. A. (1990). Cyanobacterial 
microcystin-LR is a potent and specific inhibitor of protein phosphatases 1 and $2 \mathrm{~A}$ from both mammals and higher plants. FEBS Letters, 264, 187-192.

MacKenzie, K., Williams, H. H., Williams, B., McVicar, A. H., \& Siddall, R. (1995). Parasites as indicators of water quality and the potential use of helminth transmission in marine pollution studies. Advances in Parasitology, 35, 128-144.

Matsumura, K., Mitsui, Y., Sato, K., Sakamoto, M., \& Aoki, Y. (1991). Schistosoma mansoni: Possible involvement of protein kinase $\mathrm{C}$ in linoleic acid-induced proteolytic enzyme release from cercariae. Experimental Parasitology, 72, 311-320.

McCarthy, A.M., (1999). The influence of temperature on the survival and infectivity of the cercariae of Echinoparyphium recurvatum (Digenea: Echinostomatidae). Parasitology, 118, 383388.

Morley, N. J., Irwin, S. W. B., \& Lewis, J. W. (2003). Pollution toxicity to the transmission of larval digeneans through their molluscan hosts. Parasitology, 126, 5-26.

Thieltges, D.W., Jensen, K.T. and Poulin, R., (2008). The role of biotic factors in the transmission of free-living endohelminth stages. Parasitology, 135, 407-426.

Tournebize, R., Andersen, S. S. L., Verde, F., Dorée, M., Karsenti, E., \& Hyman, A. A. (1997). Distinct roles of PP1 and PP2A-like phosphatases in control of microtubule dynamics during mitosis. EMBO Journal, 16, 5537-5549.

Paerl, H. W., \& Huisman, J. (2009). Climate change: A catalyst for global expansion of harmful cyanobacterial blooms. Environmental Microbiology Reports, 1, 27-37.

Pietrock, M., \& Marcogliese, D. J. (2003). Free-living endohelminth stages: At the mercy of environmental conditions. Trends in Parasitology, 19, 293-299. 
Prinz, K., Kelly, T. C., O'Riordan, R. M., \& Culloty, S. C. (2009). Non-host organisms affect transmission processes in two common trematode parasites of rocky shores. Marine Biology, $156,2303-2311$.

Rohr, J. R., Raffel, T. R., Sessions, S. K., \& Hudson, P. J. (2008). Understanding the net effects of pesticides on amphibian trematode infections. Ecological Applications, 18, 1743-1753.

Schell, S.C. (1970). How to know the trematodes. W. C. Brown Co., 355 pages.

Schell, S.C. (1985.) Handbook of Trematodes of North America North of Mexico. University Press of Idaho, Idaho. 263 pp.

Waajen, G. W. A. M., Faassen, E. J., \& Lürling, M. (2014). Eutrophic urban ponds suffer from cyanobacterial blooms: Dutch examples. Environmental Science and Pollution Research, 21, 9983-9994.

Warren, K. S., \& Peters, P. A. (1968). Cercariae of Schistosoma mansoni and plants: Attempt to penetrate Phaseolus vulgaris and Hedychium coronarium produces a cercaricide. Nature, 217, $647-648$.

Welsh, J. E., Van Der Meer, J., Brussaard, C. P. D., \& Thieltges, D. W. (2014). Inventory of organisms interfering with transmission of a marine trematode. Journal of the Marine Biological Association of the United Kingdom, 94, 697-702.

Williams, C. D., Aubel, M. T., Chapman, A. D., \& D'Aiuto, P. E. (2007). Identification of cyanobacterial toxins in Florida's freshwater systems. Lake and Reservoir Management, 23, 144152.

Zambrano, F., \& Canelo, E. (1996). Effects of microcystin-LR on the partial reactions of the $\mathrm{Na}+\mathrm{K}+$ pump of the gill of carp (Cyprinus carpio linneo). Toxicon, 34, 451-458. 
Zurawell, R. W., Chen, H., Burke, J. M., \& Prepas, E. E. (2005). Hepatotoxic cyanobacteria: A review of the biological importance of microcystins in freshwater environments. Journal of Toxicology and Environmental Health - Part B: Critical Reviews, 8, 1-37. 


\section{CHAPTER 4: EFFECTS OF MACROPHYTE STRUCTURAL COMPLEXITY ON AMPHIBIAN PARASITISM}

\section{Introduction:}

There are many environmental factors that could affect parasite infections. Some physical obstacles in an aquatic environment have been studied, but it is not well known how vegetation could impact parasitism. Vegetation is an integral part of a body of water, whether it is algae or macrophytes. For instance, algae blooms promote the growth and proliferation of the first intermediate hosts for trematode (flatworm) parasites that release free-swimming infectious stages (cercariae) into the water, resulting in more frequent and more severe amphibian infections (Johnson et al., 2007). Macrophytes, in turn, represent a large component of the physical structural complexity within an aquatic ecosystem. Along with other habitat alterations, changes in aquatic vegetation can occur for various reasons, from eutrophic conditions that promote the presence of primary producers to the introduction of invasive species (Zurawell et al., 2005; Katsanevakis et al., 2014). Understanding the potential influence of aquatic vegetation on host parasitism becomes even more important when considering the many invasive plant species that have been anthropologically introduced, or the widened habitat range of many due to climate change (Katsanevakis et al., 2014).

As discussed in Chapter 1, trematode parasites have a complex multi-host life cycle, and the free-swimming cercariae that emerge from the snail first intermediate hosts rely on various cues to find their second intermediate host, such as vibrations and shadows (Haas, 2003) that could be obstructed by vegetation. Dark shadows are known to invoke swimming behaviour in some cercariae, particularly those which seek active hosts (Haas, 2003). Dark shadows may serve as a host-finding cue in some cases and induce swimming, but this does not always 
stimulate attachment, suggesting that a dark shadow may invoke a defensive swimming response in some species (Haas, 2003). Shadows caused by vegetation could mimic a potential host, causing the cercariae to swim and waste energy, but could also block shadows produced by a suitable host such as a tadpole, thus preventing detection by cercariae. Conversely, physical touch serves as a cue for investigation in some cercarial species (Haas, 2003), and contact with vegetation could prompt cercariae to investigate the stimulus, also wasting energy better spent looking for hosts. Most cercariae live less than 24 hours, do not feed, and have finite energy reserves (McCarthy, 1999). Thus, spending energy on swimming and investigating non-host obstacles reduces their life-span, and thus their chance at finding a host. In very dense vegetation, this could prove to be an energy- and time-demanding process. Some cercariae also utilize water turbulence as a cue (Haas, 2003). In a similar manner, the presence of vegetation could physically obstruct or dampen water turbulence emitted by the host, thus interfering with and weakening the host-emitted signal.

Many abiotic factors in the environment could impede cercariae survival and thus host finding (see Chapter 1), including salts, high temperature, and pesticides (Morley et al., 2003; Koprivnikar et al., 2006). However, some biotic factors, such as primary producers, can serve as obstacles interfering with cercarial host finding. Christen (1976) found that certain types of plants could interfere with host finding of Schistosoma mansoni cercariae. This study largely examined surface-floating vegetation, and this is where the majority of interference was found probably because of $S$. mansoni's cercarial behaviour in the water column (Christen, 1976). Notably, S. mansoni cercariae prefer to linger around the surface of water as opposed to the sediment and are thus likely to coincide with floating vegetation as opposed to submerged vegetation. In addition, some Schistosoma species are very unspecific in terms of what stimulates 
them to attach to a substrate (Haas, 2003). Similar findings have been found in marine environments. Prinz et al. (2009) found that the infection success of cercariae was $\sim 10 \%$ in the presence of simple seaweed, compared to $2 \%$ infection success in the presence of complex algae. A structurally more complex algae (fine branching) blocked cercaria by up to $87 \%$ in another study, whereas the more simple algae (broad blades) had no blocking effect (Welsh et al., 2014). However, the experimenters did not examine whether algal exudates had a potential effect on the cercariae, and certain primary producers may secrete toxins with a cercariacidal effect (Warren \& Peters, 1968).

As mentioned above, invasive primary producers have considerable potential to affect host-parasite dynamics. In a study examining the effects of an invasive algae on fish parasitism, $46.26 \%$ of fish from sites with no invasive species were infected by six trematode species. Only two trematode species were identified in the sites taken over by the invasive algae and their prevalence was less than 2\% (Bartoli \& Boudouresque, 1997). It is likely that the algae acted as a physical barrier, but the authors also hypothesized the lower infection could be due to toxins released by the algae that directly acted on the cercariae or accumulated in hosts and prevented encystment. Regardless of whether this pattern was due to cercarial interference, it illustrates the large change in parasite community structure that can be brought on by invasive primary producers.

Many organisms engage in behaviours to actively protect themselves from parasites (Hart, 1994). Larval amphibians display anti-parasite behaviors which serve to avoid parasites and reduce infection (Koprivnikar et al., 2006). Thus, if tadpoles cannot actively avoid or dislodge cercariae upon sensing them, they can more easily get infected (Daly \& Johnson, 2011). In a similar manner to obstructing cercariae, it may be possible that vegetation could also 
obstruct a tadpole from escaping cercariae or could impair a tadpole's ability to detect cercariae, resulting in higher infection.

Interference with parasitism by physical objects often increases with their density (Christen, 1979; Thieltges et al., 2008). Thus, the complexity and density of vegetation within aquatic ecosystems could have profound effects on host parasitism, and ultimately community structure. Invasive species could especially pose a risk because introduced algae or macrophytes have the potential to completely take over and displace native vegetation, and can often be quite dense (Bartoli \& Boudouresque, 1997). The potential increase in density can be coupled with an increase in complexity if the invader is complex in shape, such as the invasive seaweed in the above example of Welsh et al. (2014) which blocked cercariae by 87\%, compared to the native species which had no effect. As such, both the structural complexity and density of aquatic macrophytes should be considered with respect to possible effects on host-parasite dynamics.

Within an aquatic ecosystem, trematodes can be quite harmful to larval amphibians. For example, Ribeiroia ondatrae causes severe limb deformities in amphibians and significantly contributes to their mortality in nature (Johnson et al., 2001). Certain primary producers, such as algae, are known to promote amphibian trematode infection (Johnson et al., 2007) by enabling the proliferation of snail hosts and thus cercarial production, but it is not known whether the physical structure of macrophytes can also affect this system in any way. Tadpoles display evasive behaviour in the presence of parasites (Taylor et al., 2004; Koprivnikar et al., 2014) and it is important to examine whether the presence of vegetation could impact a tadpole's behaviour to either increase or decrease infection. I hypothesized that infection would be lower in conditions of higher macrophyte density, as well in the presence of complex macrophytes. I predicted this would be driven by reduced tadpole activity when subjected to treatments of 
higher densities, as well as higher complexities of plants, thus resulting in more infection via decreased evasive behaviour by the hosts.

\section{Materials and methods:}

\section{Animal care}

Rana sylvatica (wood frog) eggs were obtained from a commercial supplier (Boreal Science) and kept in communal tubs until hatching. Tubs were filled with $15 \mathrm{~L}$ of tap water treated with Nutrafin ${ }^{\circledR}$ water conditioner to remove chlorine and chloramine, and Nutrafin Biosupport ${ }^{\circledR}$ to promote beneficial bacteria. This tubs were kept at $20^{\circ} \mathrm{C}$ on a $14: 10$ light/dark cycle. Upon hatching, tadpoles were distributed into twelve 15-L communal tubs at a density of $\sim 70$ tadpoles per tub and aerated with airstones. Each communal tub received a water change every 2 days, with alternating half-water changes and full water changes, and 3 rabbit chow pellets $($ Hagen $®)$ were provided at each full and partial change for the first 3 weeks of development. After 3 weeks, tadpoles were fed boiled spinach and fish food instead of rabbit chow pellets, ad libitum until they reached Gosner stage 30 (Gosner, 1960) and were only fed raw spinach.

\section{Parasite acquisition}

Snails were field collected from a pond in St. Catherines, Ontario. The collected snails were screened for trematode infection by placing them into Petri dishes with treated water and a piece of spinach under a $60 \mathrm{~W}$ incandescent lamp for 1 hour. After this, emerged cercariae were collected and viewed under a compound microscope for identification. Ribeiroia ondatraeinfected snails were separated from uninfected snails and kept in separate communal tubs with treated water and fed spinach ad libitum. The evening before the experiment, infected snails were placed into Petri dishes with treated water because $R$. ondatrae emerges overnight. At 7 am 
the morning of the experiment, actively swimming cercariae were pipetted into microcentrifuge tubes such that each microcentrifuge tube had 20 cercariae from randomly selected snails to ensure a random distribution of age and genetic diversity.

\section{Experimental design}

Plastic vegetation was obtained from Big Al's Canada and were chosen to represent both a complex and simple shape resembling common aquatic macrophytes found in local ponds. We chose 8-inch "Green Jungle Vallisneria" as our simple macrophyte that corresponds to the natural plant Vallisneria americana, while the complex plant was represented by 8 inch "Green Cabomba" which corresponds to Myriophyllum alterniflorum (Fig. 4.1). I had 4 treatments representing a factorial combination of plant complexity and density: treatment A - simple/low density, treatment B -simple/high density (2x plants of low density), treatment C - complex/low density, and treatment D - complex /high density; each treatment had 5 replicates. The low density treatments contained 5 plants whereas the high density treatments contained 9 plants (Fig. 4.2). The high density treatment was limited because tadpoles would become undetectable in behavioural analysis under extreme density treatments. The mass was kept constant between the plants, as each plant had almost identical mass (average of $1.1 \%$ difference between the two plant types). To carry out the experiments, the plants were submerged into 40-L of water in plastic containers. Tadpoles at approximately Gosner stage 30 were randomly selected from communal tubs, weighed and placed into the containers prior to commencing the experiment such that there were 5 tadpoles per replicate (container).

\section{Experimental methodology}

Two digital video cameras were set up to record tadpole behaviour during the day upon the addition of parasites. White cardboard was placed around the experimental containers to 
block any view of the experimenters so as to not disturb the tadpoles. After the 5 tadpoles were added to each container and had 15 minutes of acclimation, $100 R$. ondatrae cercariae were added into each replicate for an average dose of 20 cercariae/tadpole because tadpole mortality was shown to significantly increase if the dosage is any higher (Schotthoefer et al., 2003). I then recorded the tadpoles for the first 20 minutes of exposure of the 2 hour overall exposure period. While there were 5 replicates/treatment, I only recorded behaviour for $3 /$ treatment. After the 2 hour exposure, all 5 tadpoles from each experimental container were placed in new communal tubs labeled with their treatment (A-D) and replicate ID (1-5) and fed raw spinach ad libitum. Two days after parasite exposure, the tadpoles were euthanized by placement into a solution of buffered 1\% MS-222 and then preserved in formalin.

\section{Data collection and analysis}

Tadpoles were dissected using a dissecting scope. Their Gosner stage was determined, as well as the number of cysts which were found around the hind legs and mouth, which are common places of $R$. ondatrae infection (Johnson et al., 2004). To determine the effect of vegetation complexity and density on individual tadpole infection status (yes or no), a Generalized Linear Mixed Model (GLMM) was used. The dependent variable was given a binomial distribution with logit link function, and the categorical fixed factors were vegetation density (low or high) and vegetation complexity (low or high), as well as their interaction. Experimental tub number (categorical) and individual Gosner stage were also included as random effects. Non-significant interaction terms were dropped from models, as were nonsignificant fixed effects, to generate a final model. To determine the effect of vegetation density and complexity on cyst abundance within individual tadpoles, both infected and uninfected tadpoles were considered. For this, we also employed a GLMM with number of cysts as the 
dependent, using a Poisson distribution with log link function, and the same fixed and random effects as for the infection status model.

Tadpole behaviour was analyzed by tracking each individual tadpole in a given treatment for 20 minutes, taking binary measurements of whether the tadpole was moving (1) or not moving (0) every 20 seconds. Tadpole proximity to vegetation was quantified as a binary measure where the tadpoles were either close to vegetation (1) or not close to vegetation (0) every 20 seconds. The proximity to vegetation was kept constant by using placing a circle around each plant on the screen during viewing that corresponded to $3 \mathrm{~cm}$ diameter in the actual experimental container. To determine whether tadpole behaviour was affected by complexity and density of vegetation, a multivariate General Linear Model (GLM) was used. The response variables were the \% time active and \% time proximate to vegetation, both arcsine-square-root transformed. The fixed factors were container ID, vegetation density (low/high), and vegetation complexity (simple/complex). All analyses were carried out using IBM SPSS 23.1.

\section{Results:}

\section{Tadpole infection}

Of the 99 tadpoles, 76 became infected, and average cyst abundance was 3.28. The initial model found that vegetation density had no effect on cyst abundance $\left(\mathrm{F}_{1,95}=0.016, \mathrm{P}=0.900\right)$, and there was no significant interaction between vegetation density and vegetation complexity $\left(\mathrm{F}_{1,95}=0.024, \mathrm{P}=0.876\right)$, thus these terms were dropped. The final model for cyst abundance thus only included vegetation complexity but was not significant $\left(\mathrm{F}_{1,9}=0.456, \mathrm{P}=0.501\right)(\mathrm{Fig}$. 4.3). With respect to tadpole infection status, no significant model was achieved. Neither vegetation complexity $\left(\mathrm{F}_{1,95}=0.472, \mathrm{P}=0.494\right)$ or complexity $\left(\mathrm{F}_{1,95}=0.472, \mathrm{P}=0.494\right)$ had a significant effect, nor was there a significant interaction $\left(F_{1,95}=0.066, P=0.798\right)($ Fig. 4.4). 
Figure 4.1: Plastic vegetation used in experiments and corresponding plants from nature. The image on the left represents a simple plant whereas the one on the right represents a complex plant.
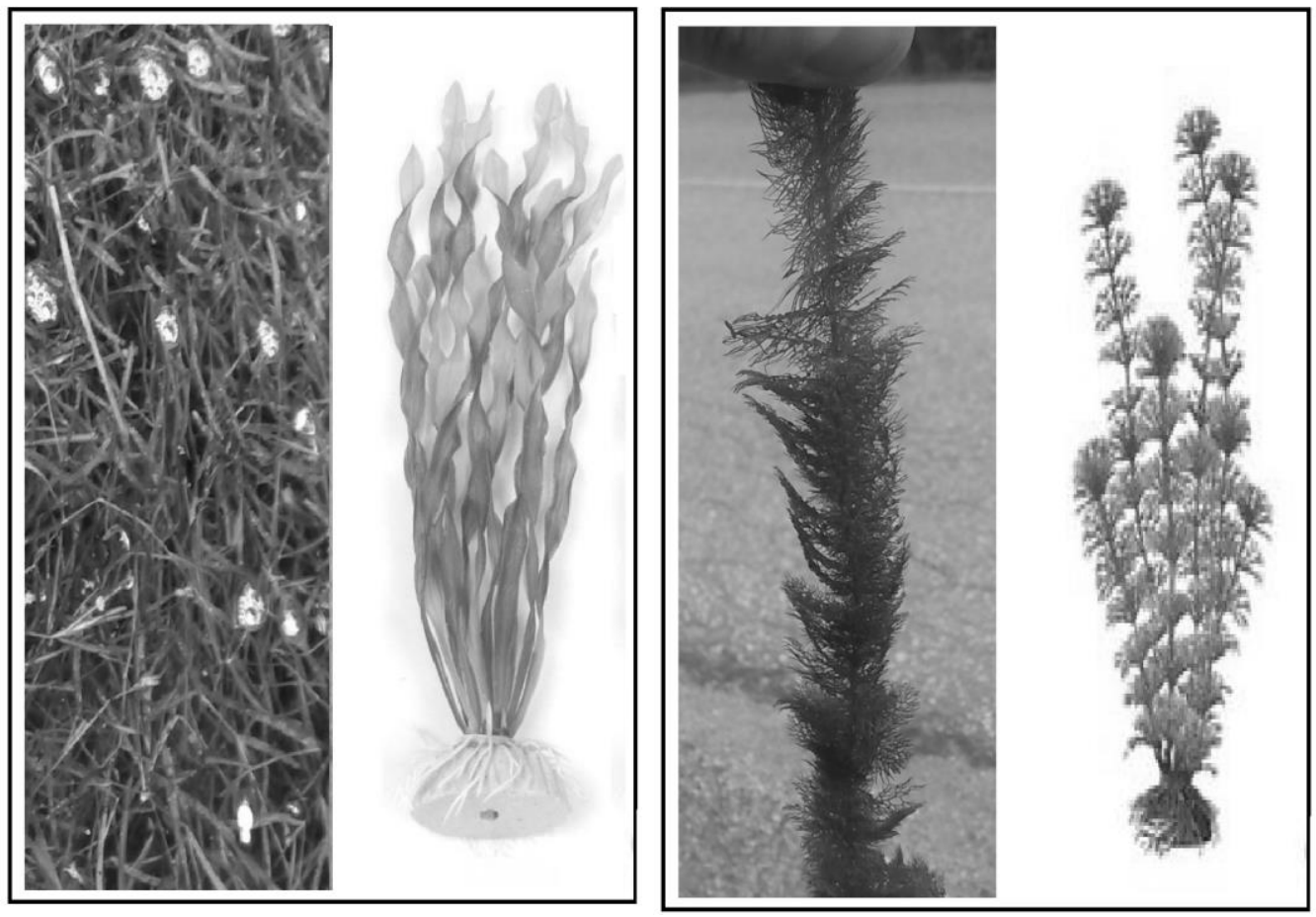
Figure 4.2: Plastic plant arrangement in the low and high density treatments. The top-down arrangement of the low density and high density treatments are shown below (left and right, respectively), with the grey circles representing individual plastic plants.
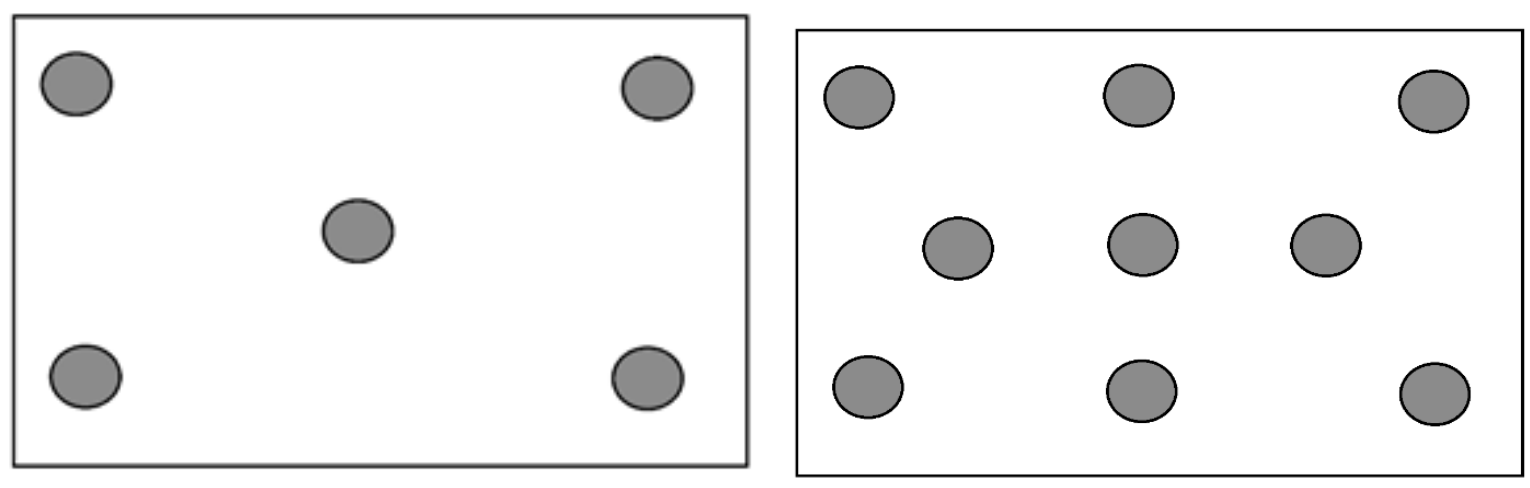
Figure 4.3: Effect of vegetation on cyst intensity (mean \pm S.E.) in tadpoles based on vegetation density ( 0 = low, $1=$ high $)$ and complexity.

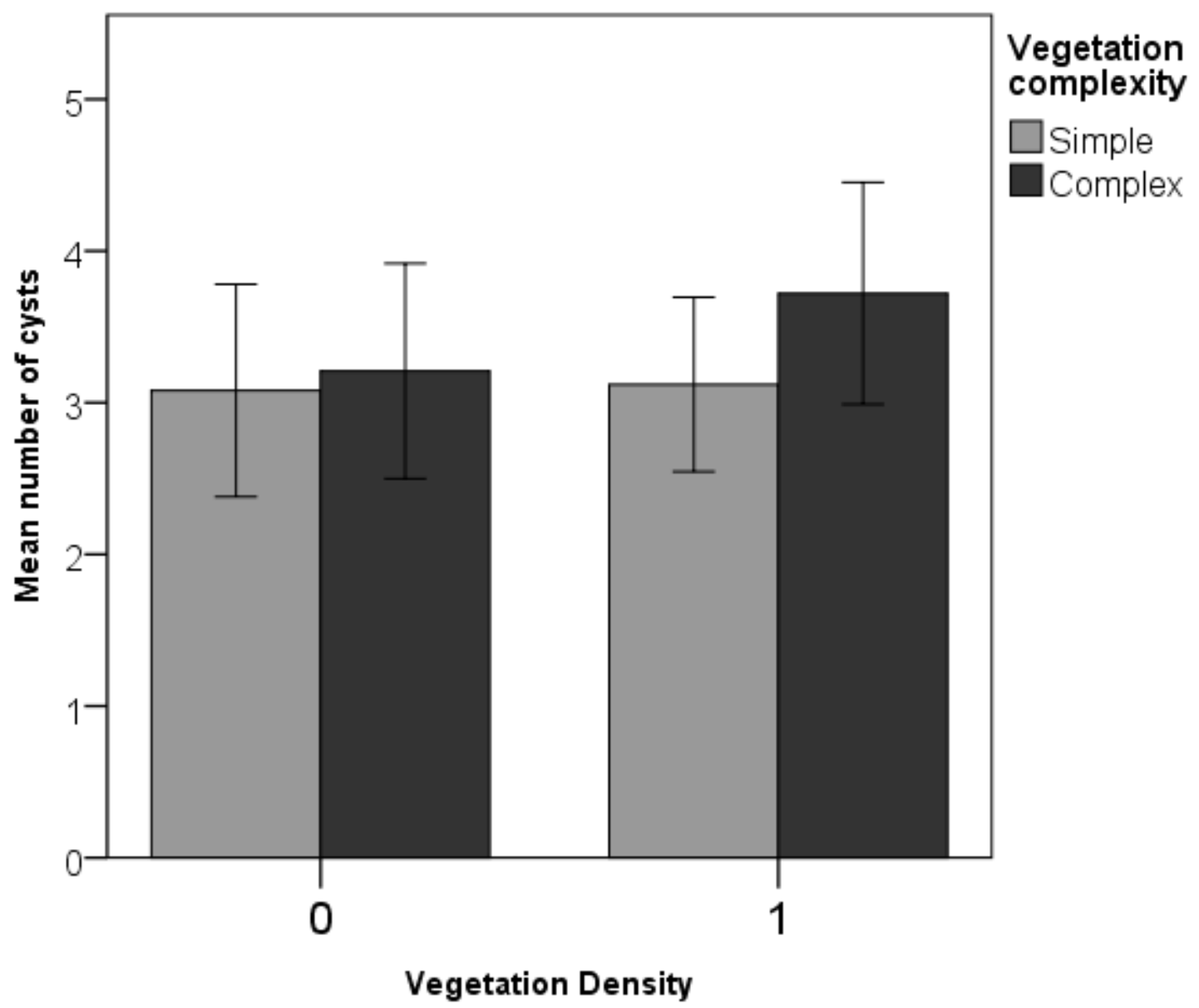

Error Bars: +/- 1 SE 
Figure 4.4: Effect of vegetation on number of infected tadpoles based on vegetation density $(0=$ low, 1 = high) and complexity.

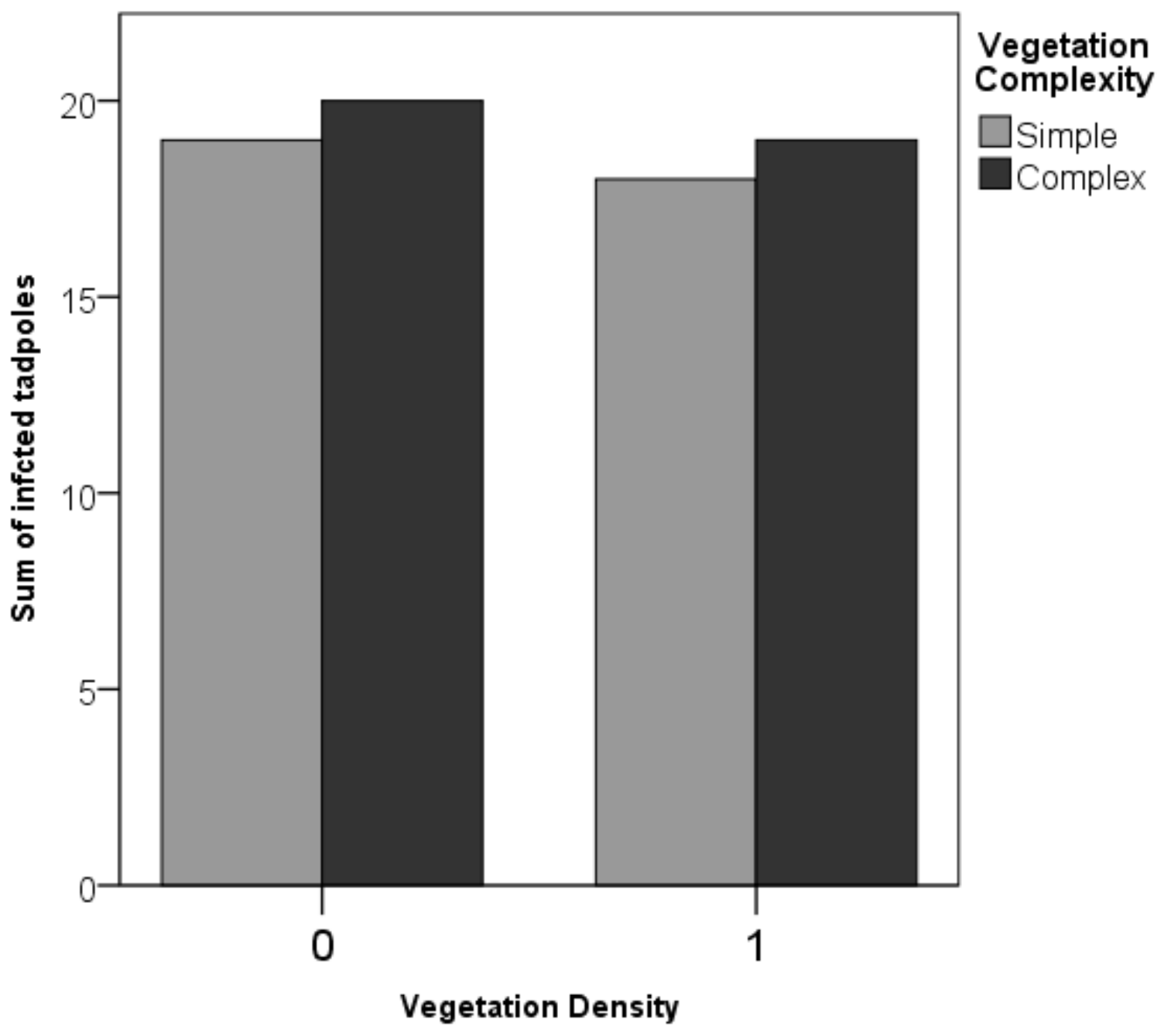




\section{Tadpole behaviour}

There was an overall effect of density on tadpole behaviour (Wilk's $\lambda_{2,53}=0.575, \mathrm{P}<$ 0.001) when considering both activity level and proximity to vegetation, but not of complexity (Wilk's $\lambda_{2,53}=0.972, \mathrm{P}=0.476$ ). The between-subjects tests indicated that the effect of vegetation density was driven by a significant effect on tadpole proximity to vegetation $\left(\mathrm{F}_{1,54}=\right.$ 34.356, $\mathrm{P}<0.001)$ rather than on tadpole activity $\left(\mathrm{F}_{1,54}=0.006, \mathrm{P}=0.607\right)$ (Figs. 4.5 and 4.6). Examined separately, vegetation complexity had no effect on tadpole activity $\left(\mathrm{F}_{1,54}=0.108, \mathrm{P}=\right.$ $0.744)$ or proximity to vegetation $\left(\mathrm{F}_{1,54}=1.532, \mathrm{P}=0.221\right)$. There was no relationship between individual tadpole activity level and time spent near vegetation as determined by a linear regression $\left(\operatorname{adj} . \mathrm{R}^{2}=0.024, \mathrm{~F}_{1,57}=2.446, \mathrm{P}=0.123\right)$. 
Figure 4.5: The effect of vegetation on proportion of time (mean \pm S.E.) that tadpoles were active in the presence of parasites based on vegetation density and complexity.

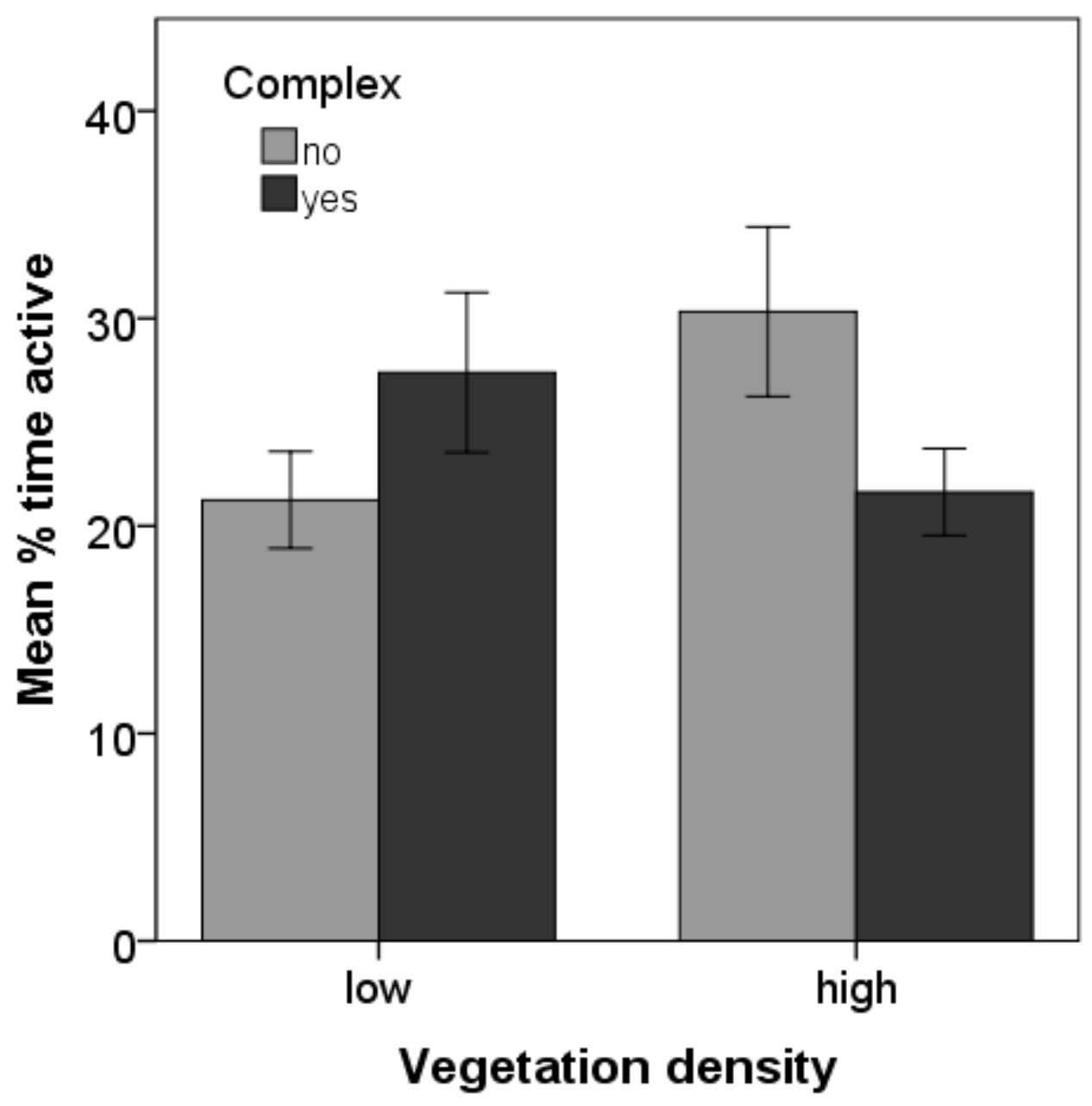

Error Bars: +/- $1 \mathrm{SE}$ 
Figure 4.6: The effect of vegetation on proportion of time (mean \pm S.E.) that tadpoles spent in proximity to vegetation based on vegetation density and complexity.

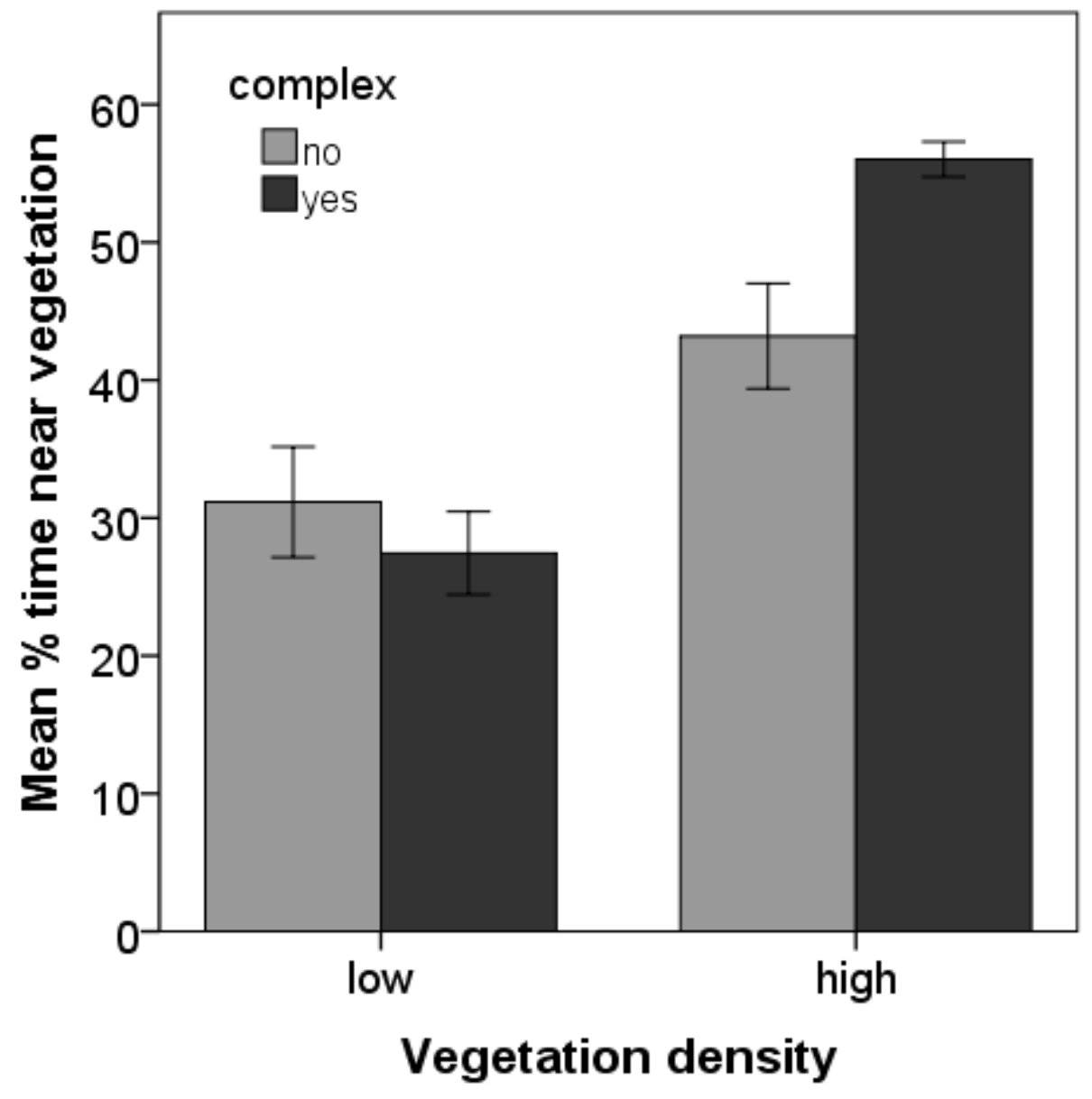

Error Bars: +/- $1 \mathrm{SE}$ 


\section{Discussion:}

There was no effect of vegetation density or complexity on tadpole infection, demonstrating that there was likely little interference with cercariae. Tadpoles in high vegetation densities or complex vegetation seemed equally able to avoid cercariae, suggesting that vegetation did not shield host-emitted cues upon which cercariae rely to find the hosts. Although other studies have shown that abiotic and biotic factors may obstruct cercariae and miracidia and thus decrease host infection (Cherning, 1968; Christensen, 1979; Bartoli, \& Boudouresque, 1997; Prinz et al., 2009; Welsh et al., 2014), this is not always so. Chernin (1968) tested whether inanimate objects (beads, pebbles and simple shells) could impede infective stages from finding their host but found no apparent effects. In another study, several plant species were examined with mixed results (Christen, 1979). Some plants had an effect only at extreme densities while others had no effect. The blocking effect was greatest when the plant material covered the surface of the water, as opposed to filling the entire space of the experimental apparatus. Effects are also highly likely to depend on the species of host and parasite in question. The behaviour of $R$. ondatrae cercariae is not well studied and it is not known whether these cercariae seek to be closer to the water surface or the sediment, what specific cues they use to detect the amphibian host, or how sensitive they are to bumping into random objects in the water. If the cercariae of $R$. ondatrae have a similar behaviour to those of $S$. mansoni, it is possible that they too would be most affected when presented with floating vegetation, as opposed to benthic vegetation. If $R$. ondatrae strongly relies on chemical cues as opposed to vibrations, any vibration-blocking effect of vegetation could serve no purpose and thus, infection could be unaffected.

Another factor for the lack of vegetative interference could be the large size of the cercariae. $R$. ondatrae cercariae are very large (Schell, 1985) and it is possible that their sheer 
size could make them less prone to obstruction by physical obstacles. Indeed, it has been suggested that behaviour as well as size could play an important role in the interaction between cercariae and interfering agents (Prinz et al., 2009). This must be further studied in $R$. ondatrae. In addition to the cercarial behaviour and size, the volume to density ratio of the experimental container in the present study may have been too high, leaving lots of empty space and not enough plants. This could translate into a low density of vegetation even at the highest density treatment, considering the density of aquatic vegetation in nature can be quite extreme (Boylen et al., 1996). With the potentially low density of plants, water turbulence or shadows caused by the tadpoles may not have been effectively disrupted by the plastic plants, thus enabling cercariae to find the host easily.

When comparing the lack of vegetation effect to other findings, several authors have found an effect of primary producers interfering with cercariae when studying the effects of complex versus simple algae, but they often simply matched the density with what was naturally found in the field. While realistic, the density of two species tested could be quite different in nature, and thus, could not show with certainty whether the effect was due to density or complexity. In studies where interference of vegetation was found, such as that of Christen (1979), it is possible that the vegetation itself did not pose a direct interference effect, but the human skin compounds left on the leaves. S. mansoni cercariae appear to be very sensitive to fatty acids (Haas, 2003). If the plants used came in contact with naked skin, trace amounts of bodily fluids could be transferred onto the vegetation, thus causing the cercariae to interpret the plant as a host. Additionally, $S$. mansoni is very sensitive to temperature gradients, $0.15^{\circ} \mathrm{C} / \mathrm{mm}$ (Haas, 2003), which could have been left on the vegetation by human contact as well.

The activity level of tadpoles was unaffected by density or complexity of vegetation. 
Tadpoles display parasite avoidance behaviour when they detect a parasite (Taylor et al., 2004; Koprivnikar et al., 2014), and it appears that this was not impeded by vegetation such that they were equally likely to be infected, and at the same intensity, regardless of treatment. However, the tadpoles did not avoid the plastic vegetation because the proportion of time spent with the vegetation increased as the density of vegetation increased. If they were repulsed by the plastics, this pattern would not be observed.

Sukhdeo and Sukhdeo (2004) suggest that a body of water is a predictable environment in terms of the flora and fauna found within it, and also the microhabitat usually used by its inhabitants. With respect to that predictable environment, they suggest that cercariae do not possess behavioural plasticity and cannot adapt to a greatly changed environment. This is particularly important with the introduction of invasive species which can alter the physical structure of the environment, changing community structure (Katsanevakis et al., 2014), and potentially introducing toxins (Warren \& Peters, 1968). Invasive species can impact single species or entire communities, displacing the native flora and fauna and reducing biodiversity by altering the environment into something more suitable for different organisms that could then lead to extirpation of endemic species (Katsanevakis et al., 2014).

The introduction of exotics could also affect parasitic disease. Johnson et al. (2002) found that the presence and abundance of planorbid snails was related to the presence of $R$. ondatrae, and if aquatic macrophytes also affect the type of snail present, there could be resulting effects on tadpole infections; however, such studies have not yet been done. In addition to blocking parasites, vegetation may interfere in other ways as well. Although not common, it was previously found that some cercariae, such as those of $S$. mansoni, may attempt to burrow into certain vegetation (Warren \& Peters, 1968). If cercariae regularly attempt to investigate or 
penetrate vegetation, it is a clear waste of time and energy, as vegetation is a dead end.

Additionally, certain plants may have cercaricidal effect (Warren \& Peters, 1968) which has further implications if certain plants have this property. Such aspects of vegetation for $R$. ondatrae also require investigation. 


\section{References:}

Bartoli, P., \& Boudouresque, C. (1997). Transmission failure of parasites (digenea) in sites colonized by the recently introduced invasive alga Caulerpa taxifolia. Marine Ecology Progress Series, 154, 253-260.

Boylen, C. W., Eichler, L. W., \& Sutherland, J. W. (1996). Physical control of eurasian watermilfoil in an oligotrophic lake. Hydrobiologia, 340, 213-218.

Chernin, E. (1968). Interference with the capacity of Schistosoma mansoni miracidia to infect the molluscan host. Journal of Parasitology, 54, 509-516.

Christensen, N. Ø. (1979). Schistosoma mansoni: Interference with cercarial host-finding by various aquatic organisms. Journal of Helminthology, 53, 7-14.

Daly, E. W., \& Johnson, P. T. J. (2011). Beyond immunity: Quantifying the effects of host antiparasite behavior on parasite transmission. Oecologia, 165, 1043-1050.

Hart, B. L. (1994). Behavioural defense against parasites: Interaction with parasite invasiveness. Parasitology, 109, 139-151.

Haas, W. (2003). Parasitic worms: Strategies of host finding, recognition and invasion. Zoology, 106, 349-364.

Johnson, P. T. J., Sutherland, D. R., Kinsella, J. M., \& Lunde, K. B. (2004). Review of the trematode genus Ribeiroia (psilostomidae): Ecology, life history and pathogenesis with special emphasis on the amphibian malformation problem. Advances in Parasitology, 57, 191-253.

Johnson, P. T. J., Chase, J. M., Dosch, K. L., Hartson, R. B., Gross, J. A., Larson, D. J., Carpenter, S. R. (2007). Aquatic eutrophication promotes pathogenic infection in amphibians. Proceedings of the National Academy of Sciences of the United States of America, 104, 15781-15786. 
Johnson, P. T. J., Lunde, K. B., Thurman, E. M., Ritchie, E. G., Wray, S. N., Sutherland, D. R., Blaustein, A. R. (2002). Parasite (Ribeiroia ondatrae) infection linked to amphibian malformations in the western United States. Ecological Monographs, 72, 151-168.

Johnson, P. T. J., Lunde, K. B., Ritchie, E. G., Reaser, J. K., \& Launer, A. E. (2001). Morphological abnormality patterns in a California amphibian community. Herpetologica, 57, $336-352$.

Koprivnikar, J., Forbes, M.R. and Baker, R.L., (2006). On the efficacy of anti-parasite behaviour: a case study of tadpole susceptibility to cercariae of Echinostoma trivolvis. Canadian Journal of Zoology, 84, 1623-1629.

Koprivnikar, J., Redfern, J. C., \& Mazier, H. L. (2014). Variation in anti-parasite behaviour and infection among larval amphibian species. Oecologia, 174, 1179-1185.

Koprivnikar, J., Forbes, M. R., \& Baker, R. L. (2006). Effects of atrazine on cercarial longevity, activity, and infectivity. Journal of Parasitology, 92, 306-311.

Katsanevakis, S., Wallentinus, I., Zenetos, A., Leppäkoski, E., Çinar, M. E., Oztürk, B., Cardoso, A. C. (2014). Impacts of invasive alien marine species on ecosystem services and biodiversity: A pan-european review. Aquatic Invasions, 9, 391-423.

Morley, N. J., Irwin, S. W. B., \& Lewis, J. W. (2003). Pollution toxicity to the transmission of larval digeneans through their molluscan hosts. Parasitology, 126, 5-26.

Prinz, K., Kelly, T. C., O'Riordan, R. M., \& Culloty, S. C. (2009). Non-host organisms affect transmission processes in two common trematode parasites of rocky shores. Marine Biology, 156, 2303-2311.

Thieltges, D. W., Bordalo, M. D., Caballero Hernández, A., Prinz, K., \& Jensen, K. T. (2008). Ambient fauna impairs parasite transmission in a marine parasite-host system. Parasitology, 135, 
$1111-1116$.

Taylor, C. N., Oseen, K. L., \& Wassersug, R. J. (2004). On the behavioural response of Rana and Bufo tadpoles to echinostomatoid cercariae: Implications to synergistic factors influencing trematode infections in anurans. Canadian Journal of Zoology, 82, 701-706.

Schotthoefer, A.M., Cole, R.A. and Beasley, V.R., (2003). Relationship of tadpole stage to location of echinostome cercariae encystment and the consequences for tadpole survival. Journal of Parasitology, 89, 475-482.

Schell, S.C. (1985). Handbook of Trematodes of North America North of Mexico. University Press of Idaho, Idaho. 263 pp.

Sukhdeo, M. V. K., \& Sukhdeo, S. C. (2004). Trematode behaviours and the perceptual worlds of parasites. Canadian Journal of Zoology, 82, 292-315.

Warren, K. S., \& Peters, P. A. (1968). Cercariae of Schistosoma mansoni and plants: Attempt to penetrate Phaseolus vulgaris and Hedychium coronarium produces a cercaricide. Nature, 217, $647-648$.

McCarthy, A.M., (1999). The influence of temperature on the survival and infectivity of the cercariae of Echinoparyphium recurvatum (Digenea: Echinostomatidae). Parasitology, 118, 383388.

Welsh, J. E., Van Der Meer, J., Brussaard, C. P. D., \& Thieltges, D. W. (2014). Inventory of organisms interfering with transmission of a marine trematode. Journal of the Marine Biological Association of the United Kingdom, 94, 697-702. 


\section{CHAPTER 5: GENERAL DISCUSSION}

Amphibians are in global decline due to a variety of factors such as habitat loss, land use changes, and various disease agents such as the chytrid fungus, ranavirus, and trematode parasites (Daszak et al., 2003). For example, the trematode Ribeiroia ondatrae causes severe limb deformities in amphibians which significantly reduces their survival in the wild (Johnson et al., 2001). There are many factors which can influence amphibian disease but the influence of primary producers was largely unknown when I commenced my experiments. In my thesis, I examined both physical aspects of aquatic vegetation (macrophytes), and also chemical aspects related to toxins produced by some phytoplankton (cyanobacteria) to see how these affected host-parasite dynamics in larval amphibians and trematode parasites. Thus, my thesis work filled gaps in knowledge regarding the effects of primary producers on parasitism in freshwater systems. More specifically, I examined the effect of the physical structure of macrophytes on infection success by free-swimming trematode infectious stages (cercariae) and tadpole antiparasite behaviour, the effect of cyanobacterial toxins on cercarial activity and longevity, and the effect of these toxins on tadpole susceptibility to infection and anti-parasite behaviour.

In marine environments, seaweed has been found to drastically decrease parasite infection through physical means (Welsh et al., 2014), but also potentially via chemical means as well (Bartoli \& Boudouresque, 1997). However, the effects of primary producers on freshwater disease dynamics have not been well studied. It is known that cyanobacterial blooms are becoming a bigger problem around the world (Paerl \& Huisman, 2009) and also have the potential to produce high concentrations of secondary compounds known as microcystins, such as microcystin-LR, i.e. MC-LR (Orihel et al., 2012). MC-LR is a known toxin and causes detrimental effects in many aquatic organisms (Zurawell et al., 2005). Just as pesticides have the 
potential to affect amphibian susceptibility and tolerance to infection (Kiesecker, 2002;

Koprivnikar, 2010), as well as cercarial survival and activity (Koprivnikar et al., 2006), it is possible that MC-LR could have the same effect.

In Chapter 2, my objective was to examine the effect of MC-LR on larval amphibian susceptibility to infection by cercariae, as well as the effect of MC-LR on larval amphibian antiparasite behaviour in the presence of cercariae. I hypothesized that when exposed to MC-LR, amphibians would be more susceptible to infection by cercariae and they would be less active (reduced anti-parasite behaviour). I found that MC-LR toxicity was variable across the two amphibian species examined. With regards to infection, there was a trend for higher infection in Rana catesbeiana (bullfrogs) when exposed to MC-LR, although a solvent effect could not be ruled out. Additionally, MC-LR had no observable effect on $R$. catesbeiana anti-parasite behaviour or growth. However, $R$. catesbeiana tadpoles were wild-caught and the results may have been confounded by other factors which could not be accounted for. In Rana pipiens (northern leopard frogs), MC-LR caused not only extremely high mortality, but also a significant increase in infection at the low concentration of $10 \mu \mathrm{g} / \mathrm{L}$. This research is unique because no one has previously examined the effects of MC-LR on larval amphibian susceptibility to trematode parasitism, or on this parameter for any animal. In addition, tadpole anti-parasite behaviour was never examined in the presence of MC-LR. Future work must be done to measure immune parameters (blood profiles) of amphibians after exposure to MC-LR. Additionally, a combination of MC-LR with other factors must be done, such as temperature, which was shown to increase MC-LR uptake (Zhang et al., 2009). Studying amphibian susceptibility to infection by other trematodes should also be carried out to see if increased susceptibility is universal across trematodes and even other disease agents. It is also important to examine within-tadpole 
infection and determine if MC-LR accumulation in certain organs could discourage parasitic encystment. Lastly, work needs to done to examine the effect of MC-LR on possible parasite avoidance by amphibians.

In Chapter 3, my objective was to examine the effects of MC-LR on cercarial activity and survival. I hypothesized that increasing MC-LR concentrations would reduce both cercariae survival and activity. I found that $100 \mu \mathrm{g} / \mathrm{L}$ MC-LR increased the longevity and activity of strigeid-type cercariae, but MC-LR did not reduce the activity or longevity of Echinostoma trivolvis, Trichobilharzia sp., or armatae-type cercariae. The results suggest that the beneficial effect of MC-LR is species-specific and varies. Different species can react differently to toxins, and the presence of MC-LR could potentially favour more certain species while causing a decrease in other species, which could impact the parasite risk faced by hosts such as tadpoles. This research is unique because no one previously examined the effect of MC-LR on trematodes. Further studies are needed to examine the effect of MC-LR on the free-swimming miracidia that infect first intermediate snail hosts to ultimately produce cercariae.

In addition, MC-LR has been found to accumulate in snail gonadal tissues (Lance et al., 2010) which is where miracidia reside. No one has yet examined the within-host effects of MCLR, and whether it can disrupt the establishment of a trematode infection in snails. MC-LR also accumulates in, and damages, the liver and intestines (Zurawell et al., 2005) so it would be interesting to examine if this could prevent parasite establishment. Studies are also needed to examine the effects of higher concentrations of MC-LR, such as those common in cyanobacterial scum, e.g. $6400 \mu \mathrm{g} / \mathrm{L}$ (Kotak \& Zurawell, 2007). Such extreme MC-LR concentrations could impact free-living trematode stages. Microcystin was found to be more easily taken up with higher temperatures (Zhang et al., 2009), and cercariae are also sensitive to temperature (Morley 
et al., 2003), so examining a possible synergistic effect of high summer temperatures in the presence of MC-LR is important. Lastly, different microcystins can be more or less toxic, depending on their hydrophobisities (Ward \& Codd, 1999), so it is important to examine several variants to establish which are most toxic when dissolved in water and which could be most toxic within host tissues.

In Chapter 4, my objective was to examine whether the structural complexity of the aquatic environment represented by macrophyte density and complexity can impact tadpole infection by trematodes, as well as tadpole behaviour in the presence of cercariae. I hypothesized that both increased density and increased complexity of plants would reduce cercarial hostfinding success, resulting in lower infections. I also hypothesized that tadpole activity would be reduced with increasing density and complexity of vegetation, resulting in higher infection. I found that vegetation density and complexity had no effect on cyst abundance, prevalence of infection, or tadpole anti-parasite behaviour. This research is unique because no one previously examined the effects of the physical structure of macrophytes on host-parasite interactions in a freshwater environment. In addition, tadpole behaviour around vegetation was not documented previously.

With climate change, the habitat range of many species is changing, allowing organisms to reach new areas of the world (Katsanevakis et al., 2014). This is important when considering invasive species because their ranges can expand as well. Invasive primary producers were already found to have drastic effects on parasitism in marine environments (Bartoli, \& Boudouresque, 1997; Welsh et al., 2014) and it is essential to study the effects in freshwater systems where such information is lacking. My results are important because they suggest that in an amphibian-trematode system, the structural complexity of the environment in the form of 
vegetation does not play a major role in cercariae host-finding or tadpole evasion. The findings suggest that physical alteration of the environment if invasive plants are introduced and reach high densities could be negligent. However, further studies need to be done with live plants, different trematode species, and more extreme densities of vegetation.

The cyanobacterial bloom problem will get worse with climate change as a warmer climate, increased stratification, decreased viscosity of water, rising $\mathrm{CO}_{2}$, increased salinity due to droughts, and rising sea water all favour the growth of toxic cyanobacteria, enabling them to outcompete other primary producers (Paerl \& Huisman, 2009). In addition, higher salt concentrations cause a leakage of microcystins from cyanobacteria (Tonk et al., 2007), which can increase MC-LR concentrations in the wild. A warmer climate not only allows for invasion of toxic cyanobacteria into areas where they were unable to colonize before (Paerl \& Huisman, 2009), but other invasives such as macrophytes (Katsanevakis et al., 2014) that have the capability to drastically alter the ecosystem structural complexity. Some macrophytes even have the potential to promote the growth of toxic cyanobacteria and thereby increase microcystin concentrations (Zurawell et al., 2005).

Soaring MC-LR concentrations are being reported, 10 - 20x higher than studied here, persisting for 9 days or more (Jones \& Orr, 1994). This could severely impact not only hosts and parasites, but many other organisms as well. Indeed, across Canadian waters, a large proportion of the lakes tested exceeded WHO guidelines for MC-LR in drinking water, as well as allowable recreational use values (Orihel et al., 2012); concentrations in Lake Erie have reached 4,500 $\mu \mathrm{g} / \mathrm{L}$ in surface scum (Michalak et al., 2013). It has even been suggested that the common sampling techniques for MC-LR are sub-optimal, thus the reported values of MC-LR in water may actually be understated and the problem bigger than previously thought (Steffen et al., 2014). 
Evidence also suggests that microbial degradation of microcystins has the potential to create a daughter compound which is even more inhibitory to protein phosphatases than MC-LR (Jones \& Orr, 1994).

Lastly, in addition to elevated temperatures favouring the expansion of invasive plants and the growth of toxic cyanobacteria, microcystin uptake is positively correlated with increasing temperature (Zhang et al., 2009), potentially worsening the problem. Freshwater ecosystems are already stressed so the introduction of invasive macrophytes or cyanobacterial blooms could contribute to further harmful effects. Understanding different ways in which these factors affect aquatic ecosystems, including disease, is thus important and urgent to predict the effects of altered primary producer communities, as well as design and implement policies and solutions to deal with this. 


\section{References:}

Bartoli, P., \& Boudouresque, C. (1997). Transmission failure of parasites (digenea) in sites colonized by the recently introduced invasive alga Caulerpa taxifolia. Marine Ecology Progress Series, 154, 253-260.

Daszak, P., Cunningham, A. A., \& Hyatt, A. D. (2003). Infectious disease and amphibian population declines. Diversity and Distributions, 9, 141-150.

Johnson, P. T. J., Lunde, K. B., Ritchie, E. G., Reaser, J. K., \& Launer, A. E. (2001).

Morphological abnormality patterns in a California amphibian community. Herpetologica, 57, $336-352$.

Jones, G. J., \& Orr, P. T. (1994). Release and degradation of microcystin following algicide treatment of a Microcystis aeruginosa bloom in a recreational lake, as determined by HPLC and protein phosphatase inhibition assay. Water Research, 28, 871-876.

Katsanevakis, S., Wallentinus, I., Zenetos, A., Leppäkoski, E., Çinar, M. E., Oztürk, B., Cardoso, A. C. (2014). Impacts of invasive alien marine species on ecosystem services and biodiversity: A pan-european review. Aquatic Invasions, 9, 391-423.

Kiesecker, J. M. (2002). Synergism between trematode infection and pesticide exposure: A link to amphibian limb deformities in nature? Proceedings of the National Academy of Sciences of the United States of America, 99, 9900-9904.

Koprivnikar, J., Forbes, M. R., \& Baker, R. L. (2006). Effects of atrazine on cercarial longevity, activity, and infectivity. Journal of Parasitology, 92, 306-311.

Koprivnikar, J. (2010). Interactions of environmental stressors impact survival and development of parasitized larval amphibians. Ecological Applications, 20, 2263-2272. 
Kotak, B. G., \& Zurawell, R. W. (2007). Cyanobacterial toxins in Canadian freshwaters: A review. Lake and Reservoir Management, 23, 109-122.

Morley, N. J., Irwin, S. W. B., \& Lewis, J. W. (2003). Pollution toxicity to the transmission of larval digeneans through their molluscan hosts. Parasitology, 126, 5-26.

Michalak, A. M., Anderson, E. J., Beletsky, D., Boland, S., Bosch, N. S., Bridgeman, T. B., Zagorski, M. A. (2013). Record-setting algal bloom in Lake Erie caused by agricultural and meteorological trends consistent with expected future conditions. Proceedings of the National Academy of Sciences of the United States of America, 110, 6448-6452.

Lance, E., Josso, C., Dietrich, D., Ernst, B., Paty, C., Senger, F., Gérard, C. (2010).

Histopathology and microcystin distribution in Lymnaea stagnalis (Gastropoda) following toxic cyanobacterial or dissolved microcystin-LR exposure. Aquatic Toxicology, 98, 211-220.

Orihel, D. M., Bird, D. F., Brylinsky, M., Chen, H., Donald, D. B., Huang, D. Y., Vinebrooke, R. D. (2012). High microcystin concentrations occur only at low nitrogen-to-phosphorus ratios in nutrient-rich Canadian lakes. Canadian Journal of Fisheries and Aquatic Sciences, 69, 1457-1462. Paerl, H. W., \& Huisman, J. (2009). Climate change: A catalyst for global expansion of harmful cyanobacterial blooms. Environmental Microbiology Reports, 1, 27-37.

Steffen, M. M., Belisle, B. S., Watson, S. B., Boyer, G. L., \& Wilhelm, S. W. (2014). Status, causes and controls of cyanobacterial blooms in Lake Erie. Journal of Great Lakes Research, 40, $215-225$.

Tonk, L., Bosch, K., Visser, P. M., \& Huisman, J. (2007). Salt tolerance of the harmful cyanobacterium Microcystis aeruginosa. Aquatic Microbial Ecology, 46, 117-123.

Ward, C. J., \& Codd, G. A. (1999). Comparative toxicity of four microcystins of different hydrophobicities to the protozoan, Tetrahymena pyriformis. Journal of Applied Microbiology, 86, 
$874-882$.

Welsh, J. E., Van Der Meer, J., Brussaard, C. P. D., \& Thieltges, D. W. (2014). Inventory of organisms interfering with transmission of a marine trematode. Journal of the Marine Biological Association of the United Kingdom, 94, 697-702.

Zhang, D., Xie, P., Liu, Y., Chen, J., \& Wen, Z. (2009). Spatial and temporal variations of microcystins in hepatopancreas of a freshwater snail from lake Taihu. Ecotoxicology and Environmental Safety, 72, 466-472.

Zurawell, R. W., Chen, H., Burke, J. M., \& Prepas, E. E. (2005). Hepatotoxic cyanobacteria: A review of the biological importance of microcystins in freshwater environments. Journal of Toxicology and Environmental Health - Part B: Critical Reviews, 8, 1-37. 